PPPL-2275

UC20-E

$\frac{126}{11265} 85(g)$

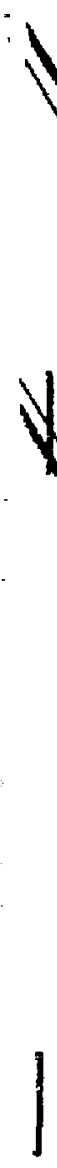

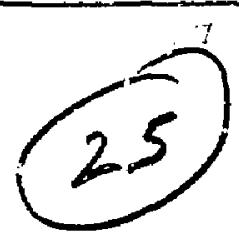

$\therefore 3816$

PPPL -2275

\title{
THREE-DIMENSIONAL MONTE CARLO CALCULATIONS \\ OF THE NEUTRON AND $\gamma$-RAY FLUENCES \\ IN THE TFTR DIAGNOSTIC BASEMENT AND \\ COMPARISONS WITH MEASUREMENTS
}

\author{
PPPL -2275 \\ DE86 002543
}

By

S.L. Liew, I.P, Ku, and J.G. Kolibal

OCTOBER 1985

\section{PLASMA PHYSICS LABORATORY}



PRINCETON UNIVERSITY

PRIJCETON, NEW JERSEY

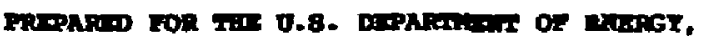
Oudath conrperes Go-MCO2-76-C.0-3073. 


\section{Three-Dimensional Monte Carlo Calculations of the Neutron and $\gamma$-ray Fluences in the TFTR Diagnostic Basement and Comparisons with Measurements}

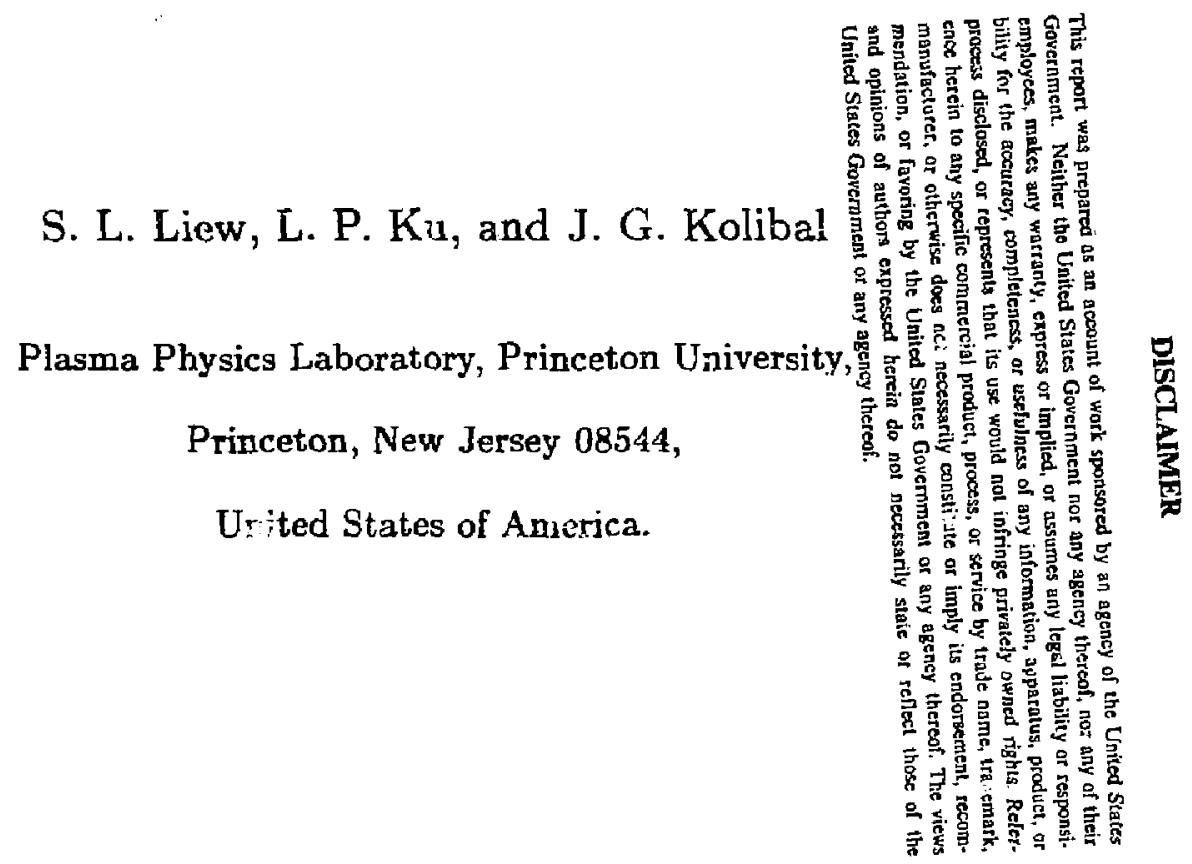

\section{ABSTRACT}

Realistic calculations of the neutron and $\gamma$-ray fluences in the TFTR diagnostic basement have been carried out with three-dimensional Monte Carlo models. Comparisons with measurements show that the results are well within the experimental uncertainties.

\section{MASTin}




\section{INTRODUCTION}

There are two important milestones in the TFTR experimental plans. One is the demonstration of the $D D$ equivalent $Q \approx 1$ operation scheduled for 1986 . The other is the achievement of DT scientific break-even in, perhaps, 1988. It is estimated that these operations will be accompanied by the generation of $10^{16}-10^{17}$ DD neutrons and $10^{18}-10^{19}$ DT neutrons per pulse, respectively. The prompt and delayed radiation fields throughout the TFTR facility due to these intense neutron sources necessitate the taking of many precautionary measures to ensure the safety of personnel and the proper functioning of various equipment, particularly the diagnostic and data acquisition systems.

To calculate the radiation levels associated with the neutron generation and to assess their impact on personnel and equipment, computational models and methods of various degrees of sophistication have been used, ${ }^{1,2,3,4}$ The models are different primarily because the appropriate methods and approximations vary accoriing to their intended applications, although some of them represent real changes imposed on the facility such as the elimination of the igloo shield and the boron coating on some parts of the concrete walls and floors. These models represent suitable compromises between the desire for accuracy and the practical need for computational efficiency. A comprehensive review and comparison of these models has been compiled. ${ }^{4}$

In all these models, major emphasis was placed on calculating the radiation levels in the test cell. The basement area was either totally ignored or greatly simplified by assuming that it was empty and by ignoring the hundreds of penetrations through the test cell floor and liue machine substructure. ${ }^{1,3}$

Various efforts have been made to address separately the effects of the penetrations on the radiation field in the basement. They range from the analysis of isolated major penetrations ${ }^{5,6}$ to the examination of small diagnostic holes. ${ }^{7}$ Since all these analyses have been carried out with simplified geometries to avoid the high cost of modelling the details, some uncertainties are inevitably associated with the results, especially those for the basement area where the important geometrical details are much more difficult to model.

It has not been possible to ascribe exact error bounds to the results because of the complexity of the problem and the lack of accurate experimental data for direct comparisons. Furthermore, it is not entirely clear how small the errors would be even if one includes every possible detail in the models.

Recently, during a series of runs with deirterium plasmas, a set of measurements was carried out in the TFTR basement and data acquisition rooms (DARM) with an NE-213 scintillation detector and a pair of Bonner spheres. ${ }^{8}$ These measurements contributed to the first set of in situ experimental data on the neution and $\gamma$-ray fluences that are useful for direct comparisons with the results of radiation transport calculations. In the interest of carrying out the comparisons, we performed a set of three-dimensional Mfonte Carlo calcu- 
lations of the prompt neutron and y-ray fluences in the basement area at some measurement positions. Details of the calculations and comparisors are given in this report.

\section{METHODS OF CALCULATION}

\section{A. General Considerations}

Given a neutron producing plasma in the TFTR vacuum vessel, the neutron fluence and the associated $\gamma$-ray fluence at a particular location in the basement depend primarily on the following factors:

1) The layout of the numerous penetrations through the machine substructure and the test cell filoor;

2) the characteristics of the penetrations, such as their sizes and the extent to which these penetrations are blocked by the filling materials, pipes, cables, etc.;

3) the distribution of materials and objects in the basement.

Of these, only the first one can be considered approximately fixed. The other two evolve with the TFTR experimental plans. Thus, one cannot have a static 'universal' model which can determine the radiation level in the TFTR basement at all operational phases.

Even if everything remains unchanged, the complicated geometrical irregularities are still practically impossible to model on present-day computers. One may appreciate the difficuity by looking at Fig. 1, which shows th numerous penetrations through the $1.83 \mathrm{~m}$ substructure beneath the machine and $F i g$. 2 , which shows a sketch of some of the structures that can be found in the basement.

The geometry of the facility, particularly the existence of several penetrations, dictates that a realistic model must be fully three-dimensional. At present. the most powerful and highly developed method of handling radiation transport problems in three-dimensional geometry is the Monte Carlo technique, which is also the most time-consuming method. The models that have been used, therefore, represent careful compromises between the desire to model the geometrical Cetails as closely as possible and the need to stay within limited computational resources.

\section{B. The Computational Models}

The calculations are grouped into two major categories. The first category is aimed at obtaining the detailed neutron and $\gamma$-ray spectra, which are to be compared with the NE-213 measurements. The second category is aimed at obtaining the total neutron Buences above cadmium cutofi $\left(\approx 0.4 \mathrm{el}^{*}\right)$, which 
arr to be compared with the Bonner sphere measurements. The models used were rather different because of the different emphases placed on the results.

\section{Calcutations of the Detailed Neutron and $\gamma$-ray Spectra}

The basic computational tool chosen for the calculations was the MCNP code. ${ }^{9,10}$ The choice was based mainly on its capability in modelling complicated geometries and the avajlability of the most recent nuclear cross-section sets. In addition, a working half geometry model of the TFTR tokamak and the test cell had already been created with the code and significant experience had been gained with the model.4 Adding the numerous penetrations and the basement would make it a rather complete and realistic three-dimensional model of the TFTR facility.

To achieve reasonable efficiency in the calculations, the TFTR test cell and the basement were modelled in quarter geometry by assuming that there were planes of symmetry along the vertical east-west and north-south planes through the machine center. These planes of symmetry were represented by reflective boundaries. Major components included in the test cell were: the vacuum vessel. TF coils, shear compression panels, inboard assembly, substructure, walls. and ceiling. Major penetrations through the substructure and the test cell floor were modelled as closely as possible. The bathtub penetrations were lined with a $0.635 \mathrm{~cm}$ layer of steel. All penetrations were assumed to be completely open. In the basement, the floor and the walls nearest to the machine center were modelled. The basement was first assumed to be empty. It was recognized that this would tend to overestimate the neutron fuence in the $\mathrm{MeV}$ region. We were interested in finding what errors would be introduced by this useful simplifying assumption.

The highly irregular structures in the basement were impossible to model in detail without a severe penalty in the computational efficiency. Thus, to approximate the shadow shielding effects due to the steel structures and experimental setups, a homogeneous cylindrical steel shell of reduced density was ised. A careful survey of the TFTR basement soon after the measurements led us to model it as the region between 2 and $6 m$ radjally from the machine center and ihroughout the height of the basement, with $4 \%$ normal density. Since the area beneaith bay $R$ was relatively clear at the time of the experimental measurements, a cut was made through the steel shell in this bay to approxinate the geometry. Figures 3-7 show the various planar cuts through the three-dimensional models. The material compositions used are given in Table I.

Source newtrons were assumed to be emitted uniformly and isotropically from a plasma region of $2.65 \mathrm{~m}$ major radius and $0.7 \mathrm{~m}$ minor radius. The source spectium was taken to be Gaussian with a temperature of $2 \mathrm{keV}$. They were followed from source energy down to $0.75 . \mathrm{KeV}$. which is the nominal lower 
currgy cutoff in the measurements.

Point detectors were placed at positions correspunding to eight detector locations in the measurements to facilitate comparisons. As given in Table? and shown in Fig. 2, four are in the northeast (NE) quadrant and the other half in the northwest (NW) quadrant. ${ }^{11}$ Since the compuser time required was roughly proportional to the number of detectors used, it would be too expensive to cover all the measured locations.

The energy grids were chosen to be the same as the ones used in unfolding the experimental data ${ }^{8}$ in order to facilitate direct comparisons, although the bin widths were known to be narrower than the energy resolution of the NE-213 devector. They are given in Table 3.

The computational efficiency was increased by using the variance reduction techniques of continuous exponential source direction biasing, geomeiry splitting and Russian roulette, implicit capture, energy and weight cutoffs. In addition, the discrete version of the recommended cross sections (drmccs3) was used throughout to reduce the computer memory requirement.

Calculation of the DD $\gamma$-ray spectrum was also carried out at a single detector location (No. 14) by following the eatire histories of the aeutrons and secondary $\gamma$-photons. The very long running time required prevented us from doing the calculation for more detector positions.

Because of the way the MCNP code handles point detectors with reflective boundaries, ${ }^{9}$ the fluences may be underestimated at some locations, especially those close to the reflective boundaries, e.g., position 10. Thus, the TFTR was also modelled in half geometry as shown in Figures 8-10 to compare with the quarter geometry resuits.

Since some fraction of DT burn would accompany the DD reactions in a deut rium plasma, calculations were pezformed for DD and DT sources separately. The composite spectra due to any fraction of DT burn could then te constructed from suitable weighted sums of these regults. One can say that all neutrons detected above $2.7 \mathrm{MeV}$ are due to the DT source component because the DD source neutrons could scarcely be born ahove this energy.

\section{Calculatione of Total Neutron Fluenceg above $0.4 \mathrm{eV}$}

The basic tool chosen for calculating the total neutron fluence was the albeda version of the MORSE Monte Carlo code. ${ }^{12,13}$ This choice was prompted by the consideration that if neutrons were followed down to the $e V$ region with the models used previously, it would require more than five times the computer time for each run, which averaged about 100 minutes on the Cray- 1 computer for four detectors. Using the MORSE cude enabled us to take advantage of the available albedo data base ${ }^{14}$ for concrete to achieve great savings in computer time. Since the energy spectra would be of much less interest in this case. the very coarse energy group structure used in the albedo dacta could he toleraced. 
To further simplify the problem, the bathtub penetrations were assumed itrlependent, and the fluence at a particular location was obtained by summing over the contribution due to each bathtub. Thus, a reference model ${ }^{5}$ was set up to include a single bathtub that penetrates the substructure into the basement. defined as a box with lateral dimensions of $26.52 \mathrm{~m}$ and a height of $5.48 \mathrm{~m}$. The bathtub was modelled simply as a rectangoular slot of $0.356 \mathrm{~m} \times 1 . \hat{0} 33 \mathrm{~m} \times$ $1.83 \mathrm{~m}$. A planar source was placed on top of the slot with the energy and angular distributions of the neutrons derived from an ANISN calculation 4,15 which modelled the machine in a one-dimensional spherical geometry. Tie basement and the penetration were assumed smpty.

\section{RESULTS AND DISCUSSION}

Results of calculations obtained with the above methods are yiver in the following sections. Where applicable, they are compared with the experimentid data. $^{*}$ For convenience, all have been normalized to one source netilon arritted from the plasma.

\section{A. Total Neutron Fluences above $0.4 \mathrm{eV}$}

Following the practice first adopted in Ref. 11, regalts obtaines with the superposition method are plotted as a function of the detector loration along with some of the results of measurements using cadmium-covered Bonner spheres, as shown in Fig. 11.

The calculated results are seen to be $20-40 \%$ higher. This is consistent with the assumption of an empty basement. The agreementi in this case should be considered excellent in view of the rather crude approximations used in the calculations. The main reason behind it is that both concrete and steei are relatively weak abscrbers of neutrons in the energy range of interest so that the total neutron fluence is rather insensitive to the distribution of these materials in the basement.

\section{B. Detailed Neutron Spectra above 0.75 MeV}

\section{Results of Calculations}

Figures 12-19 show the results of calculations at the eight detector positions chosen, assuming an empty basenent. Figures $20-27$ show the results obtained with $4-m$-reduced-density stainless steel in the basement.

In each of these plots, the dotted line shows the spectrum due to a pure DD source and the solid line shows the spectrum due to a pure DT source at $2^{i} \mathrm{c}$ the intensity of the DD source. The composite spectrum due to a DU shot with 2 ? DT burn (i.e.,2 DT reactions per $100 \mathrm{DD}$ reactions in the plasma) wotdd then 
be the sum of the two. Results obtained from foil activation neasurements ${ }^{16}$ indicated that the DT burn fraction was $\approx 1-3 \%$.

We see that the presence of the DT component would not significantly perturb the fluence in the DD region, i.e., below $2.7 \mathrm{MeV}$. This means that the effects of the DT component can be neglected when we later carry out the comparisons of DD fluences with measured data.

Comparing the two sets of results, we see that the introduction of the steel region in the basement led to significantly softer spectra and lower fluence levels at all the locations. This is due to the fact that inelastic scattering in steel is very effective in slowing down neutrons in this energy range. The slight peak at $\sim 1.2 \mathrm{MeV}$ in the DD spectrum at position 14 is mostly made up of DD source neutrons that have made one first level inelastic collision in iron.

It is also interesting to note that the $D T$ peak persigts even after the $D D$ peak has become hardly recognizable, e.g., at positions 8,9 , and 10 .

\section{Comparisons with Measurements}

Comparisons are restricted to the DD fluences since the measuret data above $\sim 5 \mathrm{MeV}$ were found to be contaminated by $\gamma$-rays ${ }^{8}$ and were deleted after the peculiar behaviors of the DT peaks were pointed out."

To facilitate direct and vivid comparisons with the experimental data, the results are again plotted against the radial distances from ihe machine center. Figures 28 and 29 show the plots for two different energy ranges: 1) 2.0-2.7 $\mathrm{MeV}$, corresponding to the DD source range, 2) 1.41-2.7 $\mathrm{MeV}$, corresponding to the range of measurements. The lower cutoff was chosen as $1.41 \mathrm{M} \mathrm{eV}$. This was because for many locations there were no experimental data below this energy, although the nominal lower cutoff in the spectrum unfolding was set at $0.75 \mathrm{MeV}$.

The detailed DD spectra calculated with reduced density steel in the basement are plotted along with the experimental data in Figures 30-42.

Figures 28 and 29 reveal the following:

1) The neutron fluence generally decreases with the radial distance from the machine center, primarily because most of the geutrons get into the basement by going through the bathtubs, which are clustered around the machine center.

2) The fuences calculated by assuming an empty basement are a factor of $2-8$ higher than the corrsponding measured values, indicating that neutron scattering with the unmodelled structures, most significantly the myriads of steel pipes and beams in the basement, cannot be neglected for neutrons in this energy range.

3) By approximating the complicated structures in the basement with at simple homogeneous shell of reduced density steel, the agreement becomes much better. For position 14, the agreement is almost perfect. For position 20, the difference is about $30^{\circ}$. For other positions, if we restrict ourselves to rlata 
taken with ohmic heating $(\mathrm{OH})$ shots, the agree:nent is withis, a factor of 2 for 1.41-2.7 $\mathrm{MeV}$, and a factor of 3 for 2.0-2.7 $\mathrm{MsV}$, except for position 8 . However. the experimental data for point 8 were obtained from a Huence level of less than $10^{2}$ neutrons $/ \mathrm{cm}^{2}$ so that the statistics may not be meaningful. It could also be that this detector was sitting behind a concrete column and was therefore seeing a lower fluence than its distance would indicate.

4) In the experimental data, the fluence levels obtained from the $\mathrm{OH}$ and neutral beam injection (NBI) shots show significant differences, ranging from 2505 is a factor of 3 . There is, however, no indication that $\mathrm{OH}$ shots would give consistently higher fuence levels per souice neutron than NBI sbots, or vice versa.

Careful examination of the detailed spectra as shown in Figures 30-42 also reveals that there are significant, though seemingly random, differences between the $\mathrm{OH}$ and NBI results. In fact, only the spectra at position 14 measured on February 13 and 14 for $O H$ shots, as plotted in Figures 40 and 41 , show true consistency. 'The calculaced spectrum aiso looks very much the same in the DD peak. However, the January 15 data, although derived again from $O H$ shots. show a markedly different spectrum, as depicted in Fig. 39. In particr $3 r$, there is a significant shift in the DD source peak. The existence of a prominent peak at about $1.2 \mathrm{MeV}$, which is higher than the source peak, is ruost likely an anomaly.

These observations suggest that the experimental uncertininies are not merely those given by the unfolcing procedure, as indicated by the error bars in the spectral plots. There were some other systematic uncertainties which would affect the reproducibility of the experimental data. This may have to do with the fact that each spectrum was derived from the cumulative counts of several shots made over a period of bours.

Without a demonstration of true consistency and reproduribility in the measured spectra for at least one location, we do not feel that it is meaningful to compare the detailed spectra and try to explain the discrepancise in the peaks and valleys, especially for locations far away from the bathtubs, where reliable statistics are more difficult to obtain, both computationally and experimentally.

Taking into account all the above observations, we can say that the results of calculations obtained with the models with reduced density steel in the basement are well within the experimental uncertainties. It is not worthwbile to refine the computational models for the comparisons unless the uncertainties in the measurements can first be narrowed down.

\section{Comparisong of Half and Quarter Geometry Models}

Figures 43-46 show the spectra obtained for positions 6 and 10 with balf and quarter geometry models.

When an empty basement is assumed, the half geometry model gives Huences 
that are consistently higher than those given by the quarter geumetry model. al.d the differences are more pronounced for position 10, which is closer to a reflective boundary. Thus, the results for an empty basement in the previous section have been under estimated by $20-100 \%$.

However, with the presence of the 4-m-reduced-density steel region. the two models give fluences which are within the statistical urcertainties. The reflective boundaries used in the quatter geometry models, therefore, did uot lead to significant under estimation of the fluences in this case. This could be attributed to the fact that the importance of collisions in regions beyond the reflective boundaries had been greatly refuced by the shaciow shielding effect of the steel region.

\section{Detailed i $D$-ray Spectrum Beneath Bay $R$}

Figure 47 shows the calculated DD $y$-ray spectrum at position 14 , which is directly beneath the bathtub peneiration at bay $R$, piotted along with the measured spectrum. There are large differences between the two. In particular, the prominent peaks at about $0.5 \mathrm{MeV}, 1 \mathrm{MeV}$, and $2.5 \mathrm{MeV}$ in the measured spectrum are all but absent from the calculated spectrum. One might argue that the peak at about $2.5 \mathrm{MeV}$ is due to the $2.2 \mathrm{MeV}$ hydrogen capture $\gamma$ rays in concrete, tat this had been taken into account in the model and it would have shown up in the calculated spectrum as well.

One possible cause for the $\sim 2.5 \mathrm{MeV}$ peak in the measured spectrum was the proximity of the Bonner sphere to the NE-213 detector during the measureinent, so that, nev wn capture by hydrogen in the polyethylene sphere would lead to significantly higher $2.2 \mathrm{MeV}$-ray fluence at the $\mathrm{NE}-213$ detector.

To examine this possibility, the $\gamma$-ray spectrum was calculated with a polyethylene sphere of radius $6.35 \mathrm{~cm}$ placed at $15 \mathrm{~cm}$ from the detector. Figure 48 shows the spectra obtained with and without the polyethylene sphere. It indicates that the presence of the polyethylene sphere led to a factor of about 2 increase in the $2.2 \mathrm{MeV} \gamma$-ray fluesce. A larger factor would have resulted had it been placed closer to the detector.

Another contributing factor is seutron capture in the scintillator itself. Although the detector volume is much smaller than the Bonner sphere, it could be just as significant because the $\gamma$-photons generated in the detector are more likely to be detected.

The large peaks at about $0.5 \mathrm{MeV}$ and $1 \mathrm{MeV}$ in the measured spectrum are due partially to the annihilation photons generated in the detector assembly and the soft iron shield surrounding the detector.

Hence, to reproduce the recorded $\gamma$-ray spectrum at any location. one would have to model all the geometrical details of the detector itself and the objects close to it at the time of the rreasurement. This was not attempted because of the iack of records of these details and of $a$ 'lequate computer time. 
On the othei: hand, since the measured $\gamma$-ray spec $v a$ actually in=lude all th $\mathrm{c}$ significant perturbations introduced by the detector and the experimental setup. they are not representative of the $\gamma$-ray spectra at the locations of measurements and should not be used directly without proper corrections for the perturbations introduced by the very ict of measurement.

\section{CONCLUSIONS AND RECOMMENDATIONS}

The results presented in this report incicate that even is- the extremely complicated geometry of the TFTR basensent, cealistic evaluations of the neutron and $y$-ray fluences can be carried out with reasonable acruracy. With proper choice of computational tools and sound judgement on the appropriate approximations usad in modelling the complicated geometry, we have obtained results that are weli within the experimental uncertainties, as the above comparisons have shown. The real restrictions imposed were the limited time and computer resources avílable rather than the modelling capabilities of the compver codes.

While the experimental data have provided useful initial guidance in setting up the models, the calculations have served to point out various prssible sources of errors and put the data in a proper perspective. These exer-ises illustrate the usefulness of the computationa' models and the proper level of confidence that should be attached to them.

Although the models have been set up here specifically for the comparisons. they are also useful for assessing all other radiatioa-reiated problems, for example, in estimating the back.ground noise levels and shielding requirements for the diagnostic systems. As the geometry of the facility evolves, the cumputational models used bere can be modified correspondingly to give reasonable estimat.:s for the new configurations. This capability is particularly valuable in evaluaring the eTects of each step in the evolution bejore it actual'y takes place.

Further checks on the models could be made by collecting a set of data in the test cell. Higher levels of neutron production in the next series of runs should give hetter statisfics in the measurements. Also, measurements of the $\gamma$-ray spectra could be improved by using a NaI detector instead of the $\mathrm{NE}-213$ detector.

\section{ACKNOWLEDGEMENT}

This work was supported by the United States Departmen: of Energy under contract No. DE-ACO2-76-CHO-3073. 


\section{REFERENCES}

${ }^{1}$ L. P. Ku, "Nuclear Radiation Analysis for TFTR," Princeton Flasma Physics Laboratory Report No. PPPL-1711, September, 1980.

${ }^{2}$ J. Kolibal and L. P. Ku, "Prompt Radiation Environment for the TETR $Q=1$ Demonstration," preseated at the 10th Symposium on Fusion Engineering, Philadelphia, December, 1983.

${ }^{3}$ J. G. Kolibal, L. P. Ku and S. L. Liew, "Two-Dimensional Prompt Radiation Analyses for the TFTR," Princeton Plasma Physics Laboratory Engineering Analysis Division Report, EAD-R-33, 1985.

${ }^{4}$ L. P. Ku, J. G. Kolibal and S. L. Liew, " $A$ Comparison of 1-, 2- and 3Dimensional Modeling of the TFTR Tokamak for Nuclear Radiation Transport Analysis," Princeton Plasria Physics Laboratory Report No. PPPL2244, August, 1985.

${ }^{5}$ J. Kolibal, L. P. Ku and S. L. Liew, "Shielding Analysis of the Major Penetrations through the $1.83 \mathrm{~m}$ Substructure of the TFTR, ${ }^{n}$ Princeton Plasma Plyysics Laboratory Engineering Analysis Division Report, EAD-R-26, 1985.

${ }^{5}$ L. P. Ku, S. L. Ijew and J. G. Kolibal, "A Parametric Analysis of Neutron Streaming Through Major Penetrations in the 0.914..1 TFTR Test Cell F'oor," Princeton Plasma Physics Laboratory Report No. PPPL-2243, August, 1985.

${ }^{7}$ L. P. Ku and J. G. Kolib. I, "Neutronic Calculations for the Tolamak Fusion Test Reactor Diagzostic Penetrations," Nuclear Technology/Fusion 2, 313, 1982.

${ }^{8}$ F. Y. Tsang, C. E. Clifford and H. Conrads, "Total Neutron Fluence and Spectral Measurement in the TFTR Test Cell Basement and the DARMs," Princeton Plasma Physics Laboratory Technical Systems Division Report. TSD-R-8, August, 1985.

${ }^{9}$ Los Alamos Radiation Transport Group, "MCNP - A General Monte Carlo Code for Neutron and Photon Transport, Version 2B," Los Alamos National Labotatory Manual LA-7396-M, Revised (April 1981).

${ }^{10} \mathrm{~J}$. Briesmeister, "MCNP Version 3 Newsletter for NMFECC," Los Alamos National Laboratory memorandum to NMFECC MCNP Distribution, March 22, 1984 (unpublished).

${ }^{11}$ S. L. Liew to R. Jittle, "Calculations of the TFTR Basement Neutron Fluences and Comparisuns with Measurements," Princeton Plasma Physics I-abora-

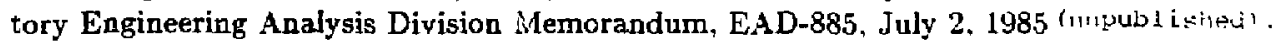

12 "MORSE-CG: A General Purpose Monte Carlo Multigroup Veutron and Gamma-Ray Transport Code with Combinatorial Geometry." RSIC Computer Code Collection, CCC-203.

${ }^{12}$ V. R. Cain and M. B. Emmett, "BREESE-II: Auxiliary Routines for Impleneating the Albedo Option in the MORSE Monte Carlo Code." ORYL/TML- 
6807, RSIC-PSR-143, July, 1979.

${ }^{14}$ M. B. Emmett and W. A. Rhoades, "CARP: A Computer Code and Albede Data Library for Use by BREESE, the MORSE Albedo Package," ORNL/TM6503, RSIC-PSR-131, October, 1978 (Updatcd 5/24/82).

${ }^{15}$ L. P. Ku and J. Kolibal, "ANISN/PPL-C, A One-Dimensional Multigroup Discrete Ordinates Code, A User's Guide," Princeton Plasma Physics Laboraiory Engineering Analysis Division Report, EAD-R-11, 1982.

${ }^{16} \mathrm{E}$. Nieschmidt (private communication). 


\begin{tabular}{|c|c|c|}
\hline Material & Element & Atoms/cm-barn \\
\hline \multirow[t]{4}{*}{$\overline{\mathrm{SS}-304}$} & $\overline{\mathbf{C r}}$ & $1.738 \times 10^{-2}$ \\
\hline & $\mathrm{Mu}$ & $1.188 \times 10^{-3}$ \\
\hline & $\mathrm{Fe}$ & $6.132 \times 10^{-2}$ \\
\hline & $\mathrm{Ni}$ & $6.793 \times 10^{-3}$ \\
\hline \multirow[t]{5}{*}{ Nitronic-33 } & $\overline{\mathrm{Si}}$ & $1.662 \times 10^{-3}$ \\
\hline & $\mathrm{Cr}$ & $1.616 \times 10^{-?}$ \\
\hline & Mn & $1.105 \times 10^{-2}$ \\
\hline & $\mathrm{Fe}$ & $5.434 \times 10^{-2}$ \\
\hline & $\mathrm{Ni}$ & $2.386 \times 10^{-3}$ \\
\hline \multirow[t]{8}{*}{ T. F. Coil } & $\overline{\mathrm{H}}$ & $4.397 \times 10^{-3}$ \\
\hline & B & $3.432 \times 10^{-4}$ \\
\hline & $\mathrm{C}$ & $1.840 \times 10^{-3}$ \\
\hline & 0 & $4.998 \times 10^{-3}$ \\
\hline & Al & $2.340 \times 10^{-4}$ \\
\hline & $\mathrm{Si}$ & $1.178 \times 10^{-3}$ \\
\hline & $\mathrm{Ca}$ & $4.212 \times 10^{-4}$ \\
\hline & $\mathrm{Cu}$ & $7.215 \times 10^{-2}$ \\
\hline \multirow[t]{10}{*}{ Ordinary Concrete } & $\overline{\mathbf{H}}$ & $7.830 \times 10^{-3}$ \\
\hline & 0 & $4.385 \times 10^{-2}$ \\
\hline & $\mathrm{Na}$ & $1.048 \times 10^{-3}$ \\
\hline & $\mathrm{Mg}$ & $1.486 \times 10^{-4}$ \\
\hline & $\mathrm{Al}$ & $2.389 \times 10^{-3}$ \\
\hline & $\mathrm{Si}$ & $1.580 \times \mathrm{i}^{-2}$ \\
\hline & $S$ & $5.635 \times 1 n^{-5}$ \\
\hline & K & $6.932 \times 10^{-4}$ \\
\hline & $\mathrm{Ca}$ & $2.915 \times 10^{-3}$ \\
\hline & $\mathrm{Fe}$ & $3.127 \times 10^{-4}$ \\
\hline \multirow[t]{13}{*}{ PPPL-308 Concrete } & $\overline{\mathrm{H}}$ & $8.246 \times 10^{-3}$ \\
\hline & $\mathrm{B}$ & $1.097 \times 10^{-3}$ \\
\hline & $\mathrm{C}$ & $1.052 \times 10^{-2}$ \\
\hline & 0 & $4.322 \times 10^{-2}$ \\
\hline & $\mathbf{N a}$ & $1.310 \times 10^{-5}$ \\
\hline & $\mathrm{Mg}$ & $1.882 \times 10^{-4}$ \\
\hline & Al & $2.634 \times 10^{-4}$ \\
\hline & $\mathrm{Si}$ & $1.091 \times 10^{-3}$ \\
\hline & $S$ & $8.077 \times 10^{-5}$ \\
\hline & $\mathrm{K}$ & $1.386 \times 10^{-5}$ \\
\hline & $\mathrm{Ca}$ & $1.308 \times 10^{-2}$ \\
\hline & $\mathrm{Fe}$ & $1.499 \times 10^{-t}$ \\
\hline & $\mathrm{Ba}$ & $1.245 \times 10^{-4}$ \\
\hline
\end{tabular}

Table 1: Atomic densities of materials used in the models. 


\begin{tabular}{||c|c|c||}
\hline $\begin{array}{c}\text { Measurement } \\
\text { Position § }\end{array}$ & $\begin{array}{c}\text { Radial } \\
\text { Distance (cm) }\end{array}$ & $\begin{array}{c}\text { Clockwise } \\
\text { Angle (deg) } \dagger\end{array}$ \\
\hline$\underline{1}$ & 1160 & 312 \\
$\underline{3}$ & 932 & 318 \\
$\mathbf{3}$ & 925 & 328 \\
$\mathbf{5}$ & 1024 & 339 \\
$\underline{6}$ & 780 & 0 \\
7 & 924 & 31 \\
$\underline{8}$ & 941 & 33 \\
$\underline{9}$ & 1109 & 37 \\
$\underline{10}$ & 850 & 54 \\
11 & 734 & 69 \\
14 & 731 & 110 \\
15 & 215 & 312 \\
16 & 1360 & 293 \\
17 & 1280 & 282 \\
18 & 1277 & 250 \\
$\underline{20}$ & 1640 & 248 \\
28 & 520 & 312 \\
29 & 1118 & 257 \\
30 & 761 & 225 \\
31 & 586 & 160 \\
32 & 705 & 141 \\
& 1376 & 29 \\
\hline
\end{tabular}

Notes:

$\S$ All positions were $60 \mathrm{~cm}$ off the floor, except position 4 which was $310 \mathrm{~cm}$. Positions used in the calculations are underlined. (For some reasons, a last minute change in the detector numbering scheme was made in Ref. 8 . We shall retain the original numbering scheme as given in Ref. 11 to avoid re-editing of this report since only the detector coordinates are of real significance.)

+ Measured from the major axis of the machine.

$\ddagger$ Measured from the project north.

Table 2: Coordinates of the detector positions used in measurements and calculations. 


\begin{tabular}{||c|c|c||}
\hline $\begin{array}{c}\text { Group } \\
\text { Number }\end{array}$ & $\begin{array}{c}\text { Upper Neutron } \\
\text { Energy (MeV) }\end{array}$ & $\begin{array}{c}\text { Upper } \gamma \text {-ray } \\
\text { Energy (MeV) }\end{array}$ \\
\hline 1 & 15.20 & 9.40 \\
2 & 13.32 & 7.97 \\
3 & 12.03 & 7.14 \\
4 & 9.32 & 5.17 \\
5 & 7.40 & 3.88 \\
6 & 5.48 & 2.67 \\
7 & 4.20 & 1.92 \\
8 & 3.10 & 1.30 \\
9 & 2.70 & 1.09 \\
19 & 2.45 & 0.97 \\
11 & 2.25 & 0.87 \\
12 & 2.00 & 0.75 \\
13 & 1.80 & 0.66 \\
14 & 1.60 & 0.57 \\
15 & 1.41 & 0.49 \\
16 & 1.22 & 0.41 \\
17 & 1.03 & 0.34 \\
18 & 0.90 & 0.29 \\
- & 0.75 & 0.24 \\
\hline
\end{tabular}

Table 3: Energy group structures used. 


\section{Figure Captions}

Figure 1: Plan view of major penetrations through the $1.83 \mathrm{~m}$ machine substruectere.

Figure 2: Sketch of some major structures that can be found ir the TFTR diagnostic basement and the approximate laycut of some positions chosen for measurements.

Figure 3: Vertical cut through the quarter geomecry model showing the tokamak, test cell, and basement.

Figure 4: Vertical cut through the quarter geometry model showing the major tokamak components.

Figures 5 and 6: Horizontal cuts through the quarter geometry models showing the major tokarak components.

Figure 7: Harizontal cuts througb the quarter geometry models showing the major penetrations through the machine substructure and the test cell floor.

Figure 8: Verfical cut through the half geornetry model showing the tokamak, test cell, and basement.

Figure 9: Horizontal cut through the half geometry model showing the major rolkamak components. 
Figure 10: Horizontal cut throligh the half geometry model showing the major penetrations $t$ l.rough the marhine substructure and the test cell floor.

Figure 11: Calculated and measured neutron fuences above cadmium cutof $v s$ the radial distances from the machine center.

Figures 12 19: Calculated neutron spectra above $0.75 \mathrm{MeV}$ using the quarter geometry models with an empty basement. The dotted lines are for one pure DD source neutron and the solid lines are for 0.02 pure DT source neutron. The error bars stand for the estimated standard deviations due to statistics.

Figures 20-27: Same as Figures 12-19 except that a 4-m-reduced-density stainless steel regir.n was modelled.

Figure 28: Calculated and measured neutron fuences in the $2.0-2.7 \mathrm{MeV}$ range vs radial distances from the machine center.

Figure 29: Calculated and measured neutron fluences in the $1.41-2.7 \mathrm{MeV}$ range vs radial distances from the machine center.

Figures 30-42: Comparisons between measured neutron spectra (dotted lines) and the DD neutron spectra calculated (solid lines) with reduced density steel in the basement.

Figures 43 and 44: Comparisons between calculated spectra using half (solid lines) and quarter (dotted lines) geometry models with an empty basement.

Figures 45 and 46: Comparisons bet.seen calculated spectra using half (solid lines) and quarter (dotted lines) geometry models with reduced density iteel in the basement. 
Figure 47: Calculated DD $\gamma$-ray spectrum (solid lines) at pusition 14 cornpared with the measured spectrum (dotted lines).

Figure 48: Calculated DD $\gamma$-ray spectra at position 14 with (solid lines) and without (dotted lines) a Bonner sphere adjacent to the detector. 


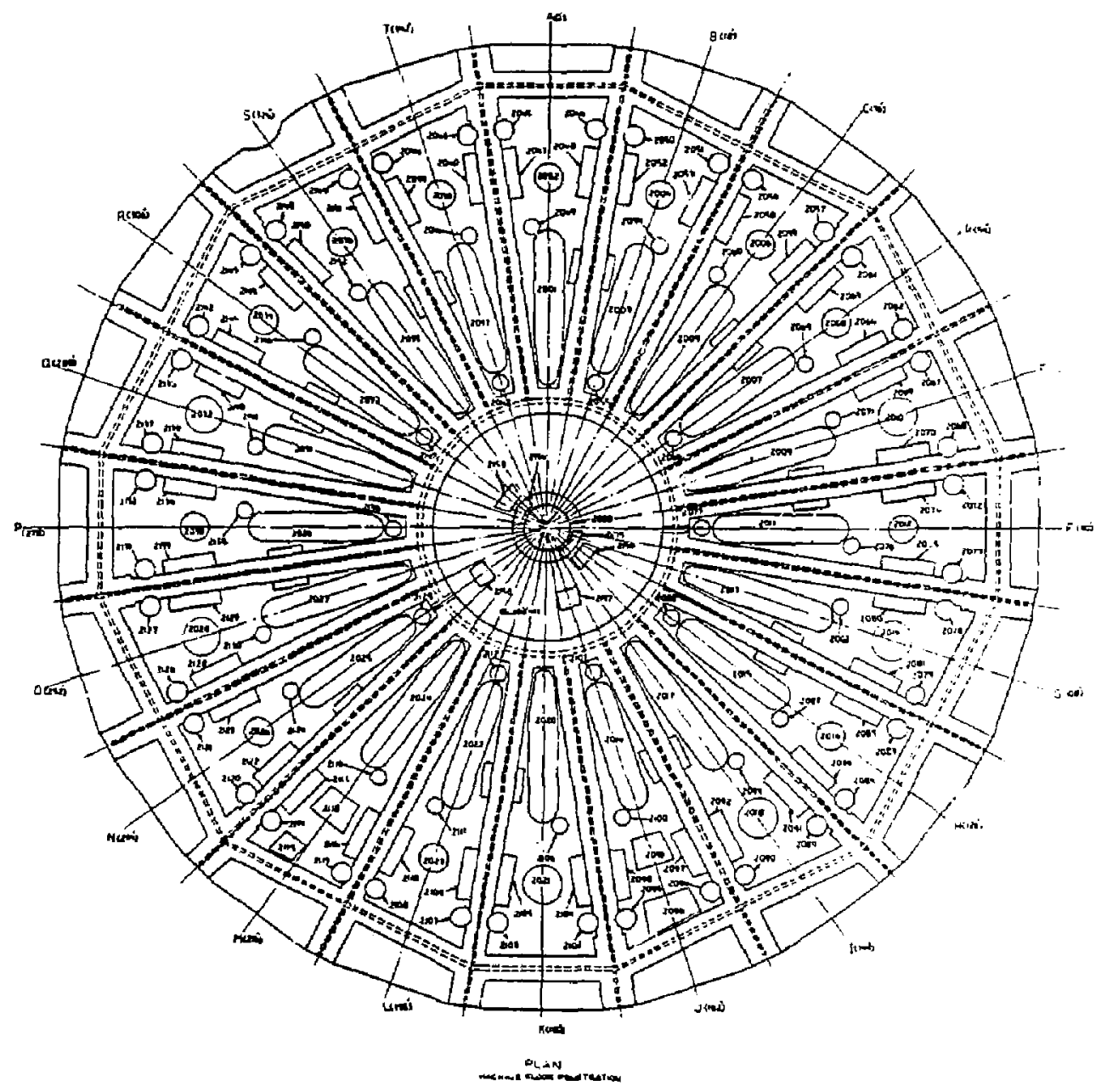

Fig. 1 


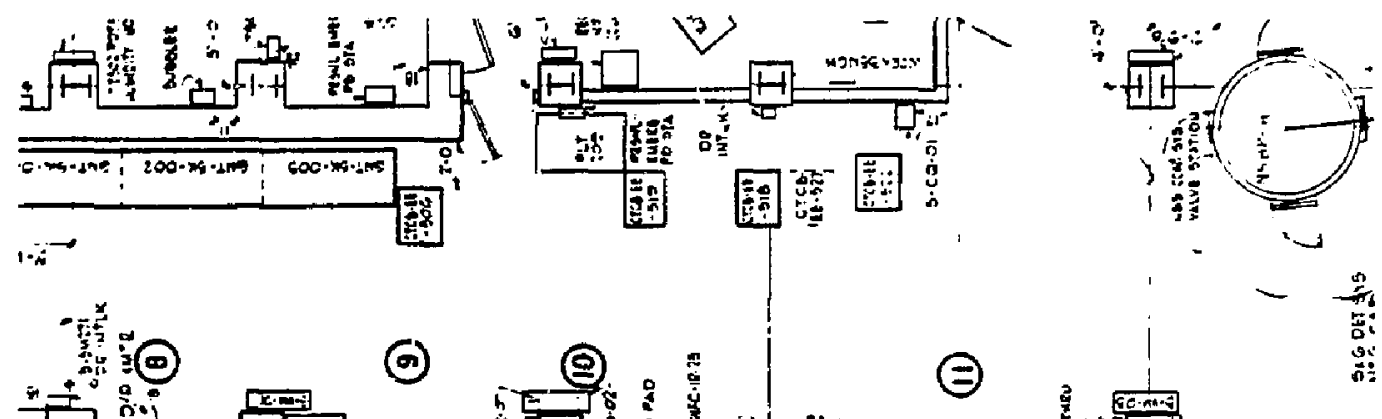

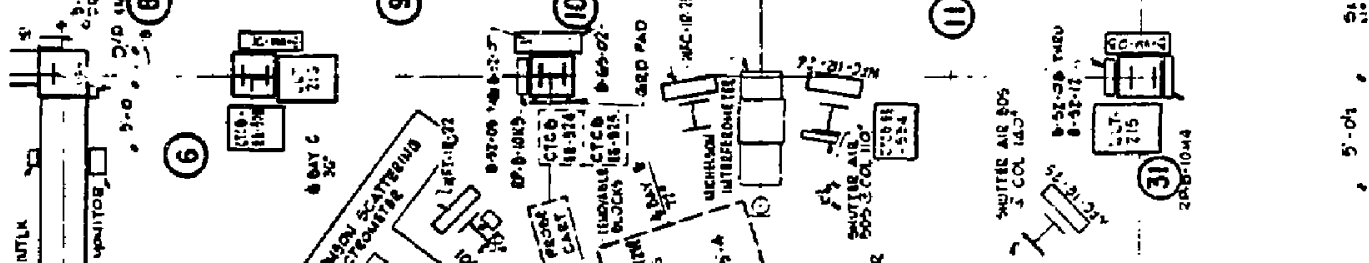
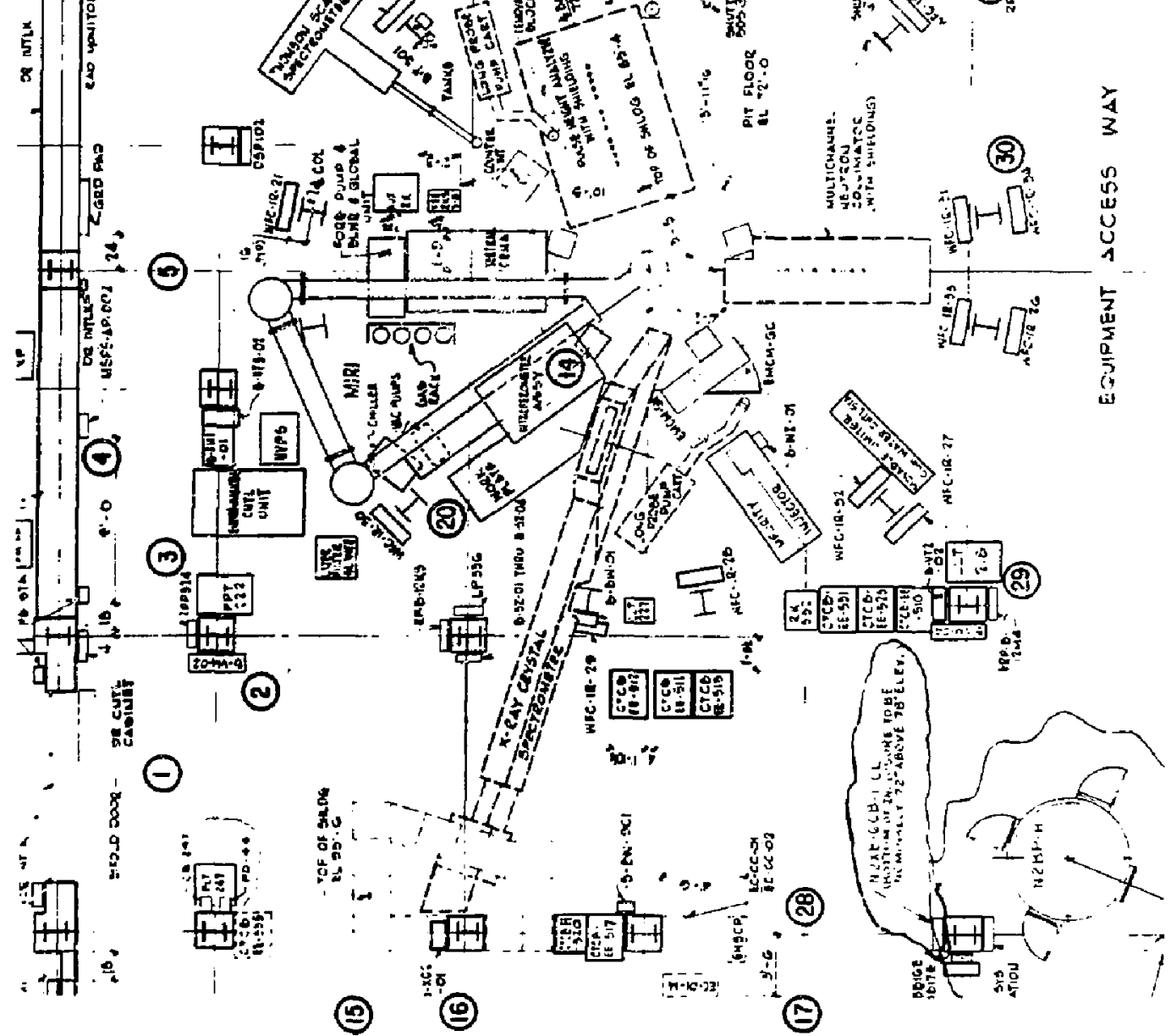
Scole:

$$
\stackrel{2 m}{\longrightarrow}
$$

T.C. Ceiling



Fig. 3 


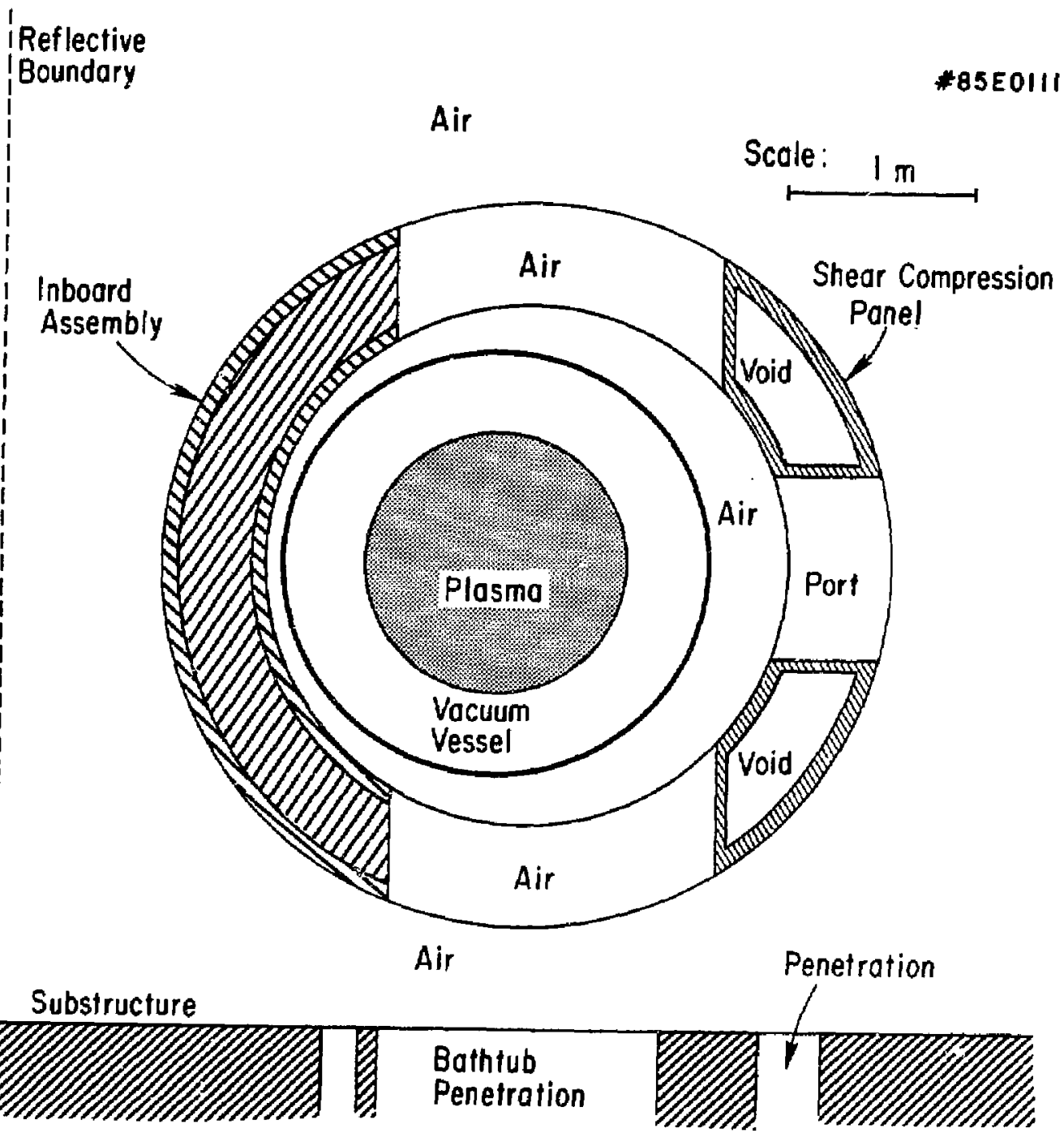

Fig. 4 


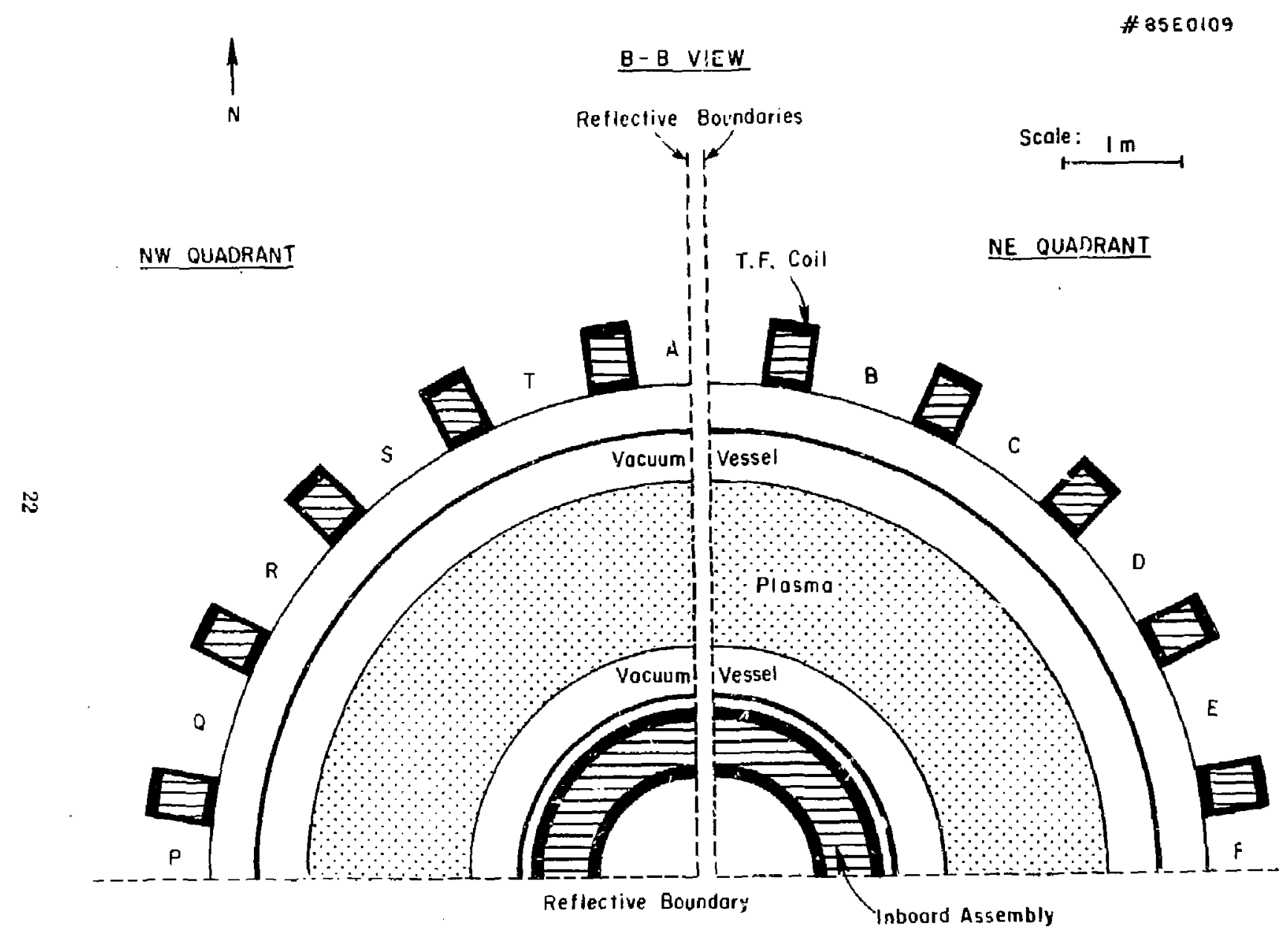

rig. 5 


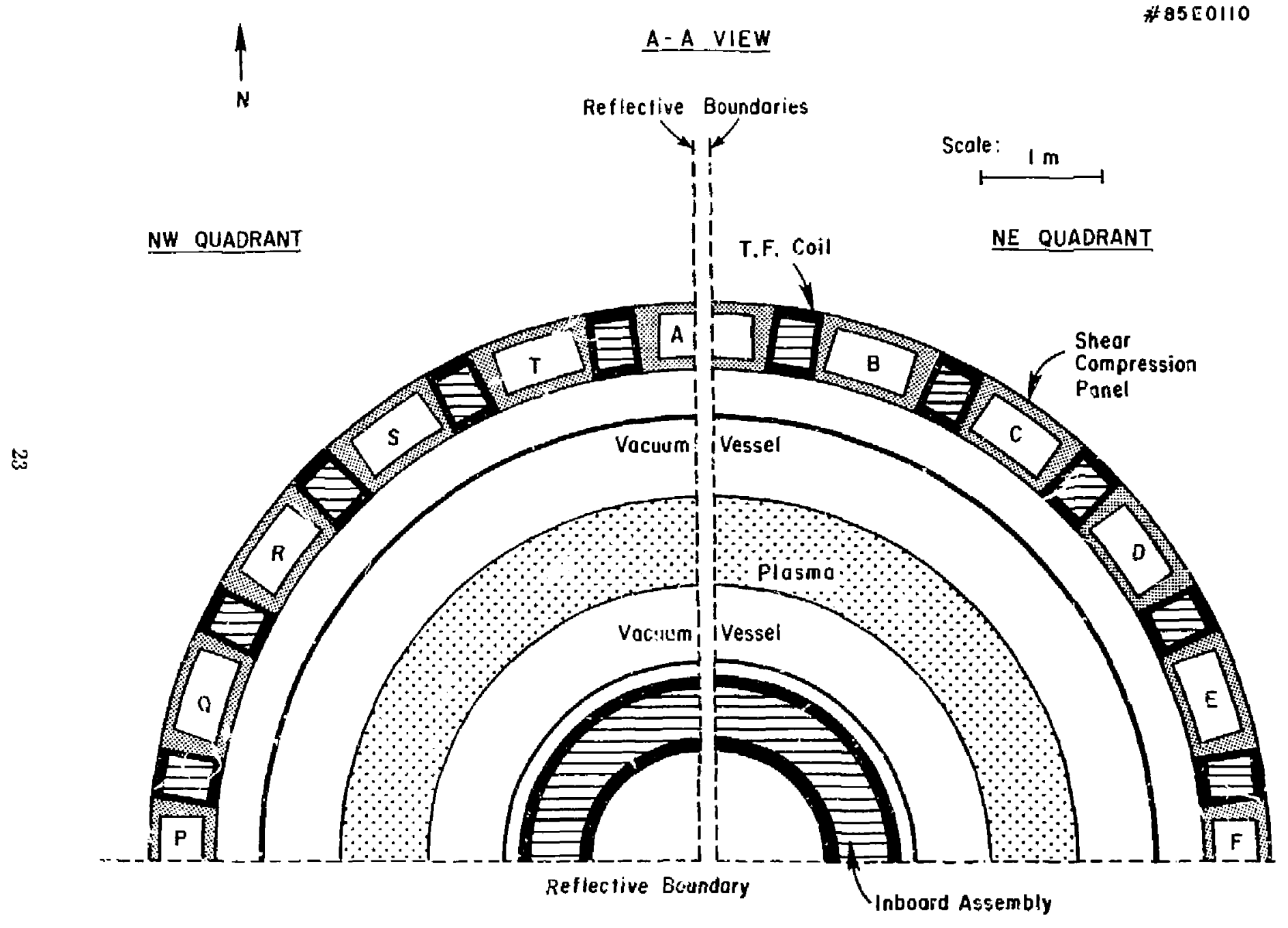

Pig. 6 


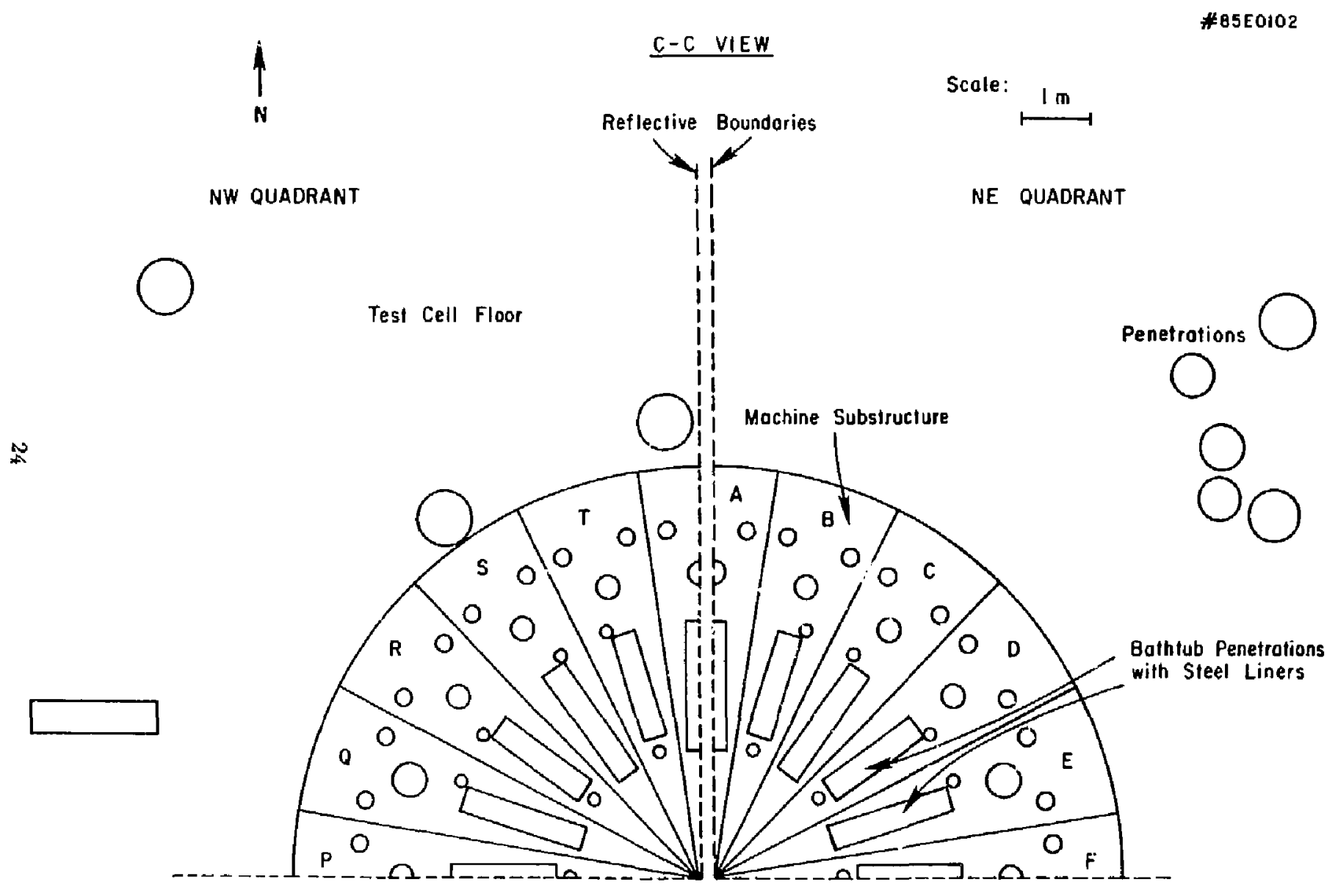

Fig. 7 




Pig. 8 
\#85E0108

\section{A-A VIEW}

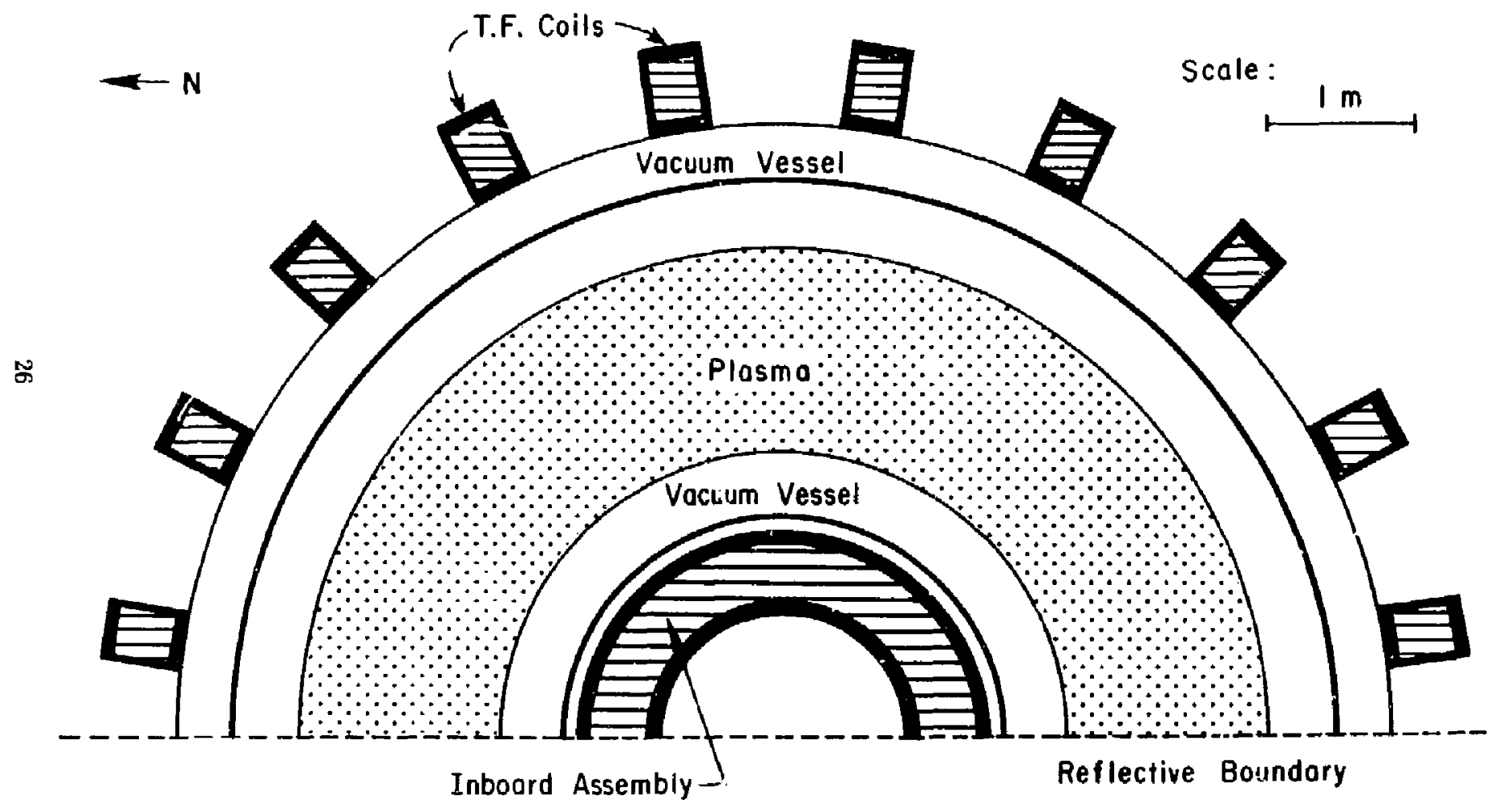

Fig. 9 


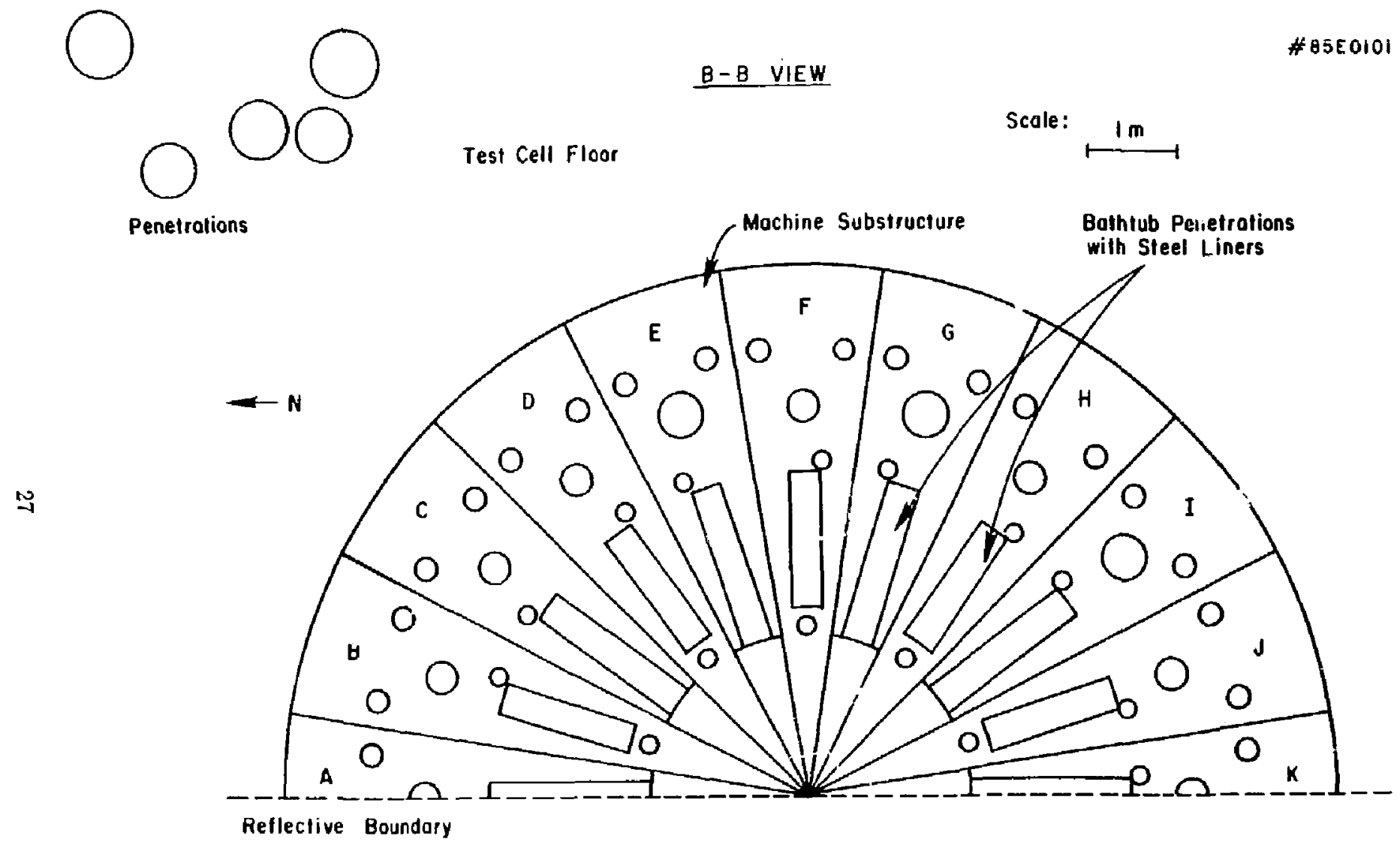

Fig. 1! 


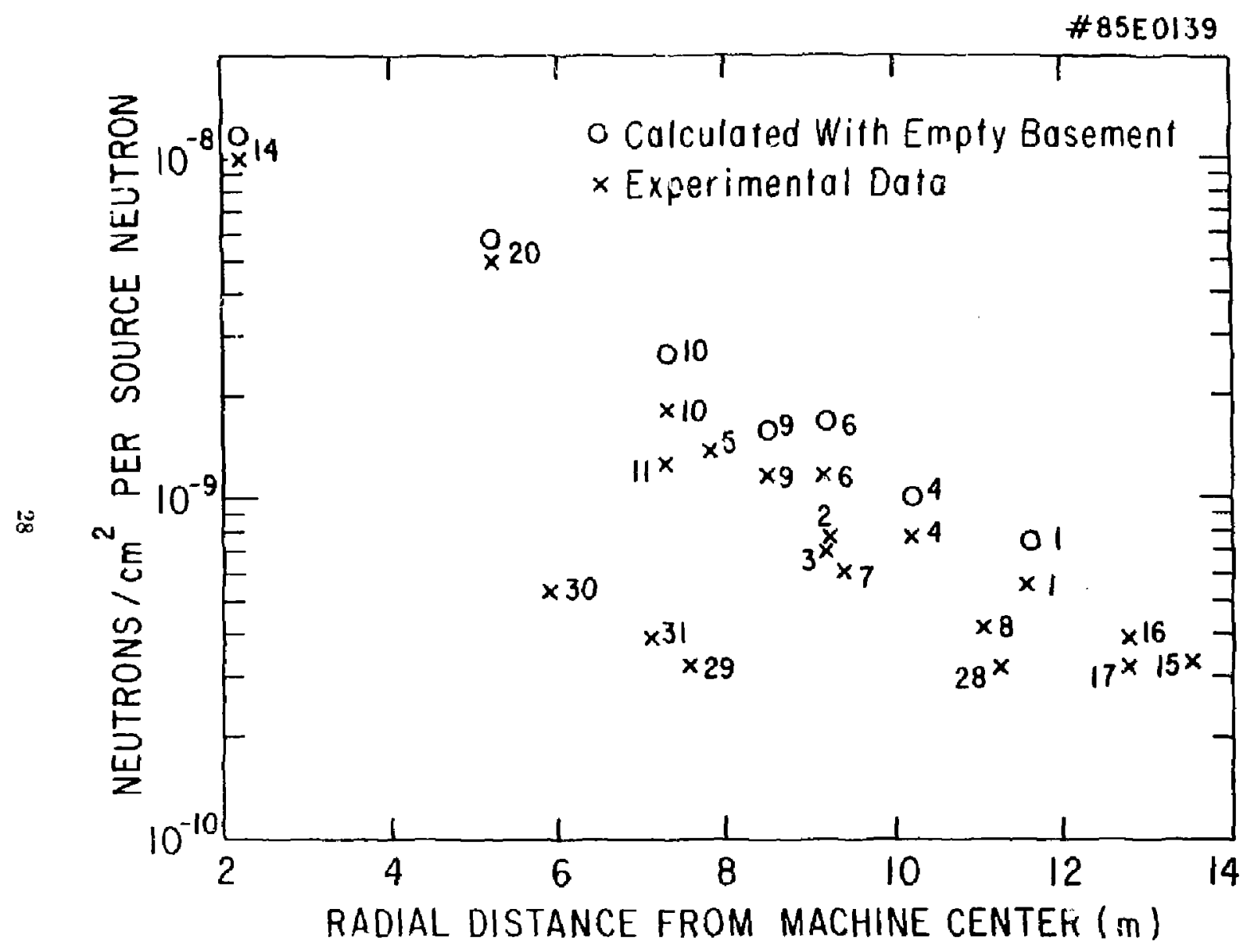

Fig. 11 


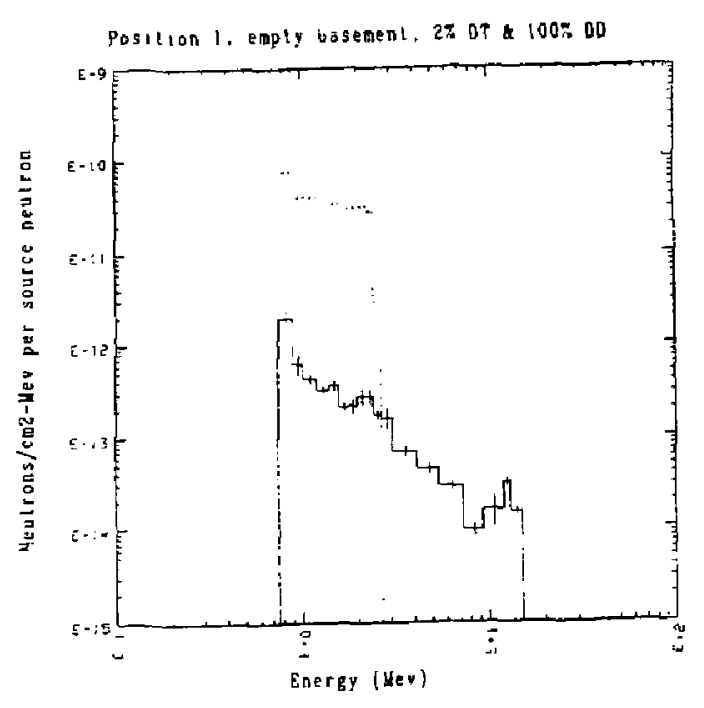

Fig. 12

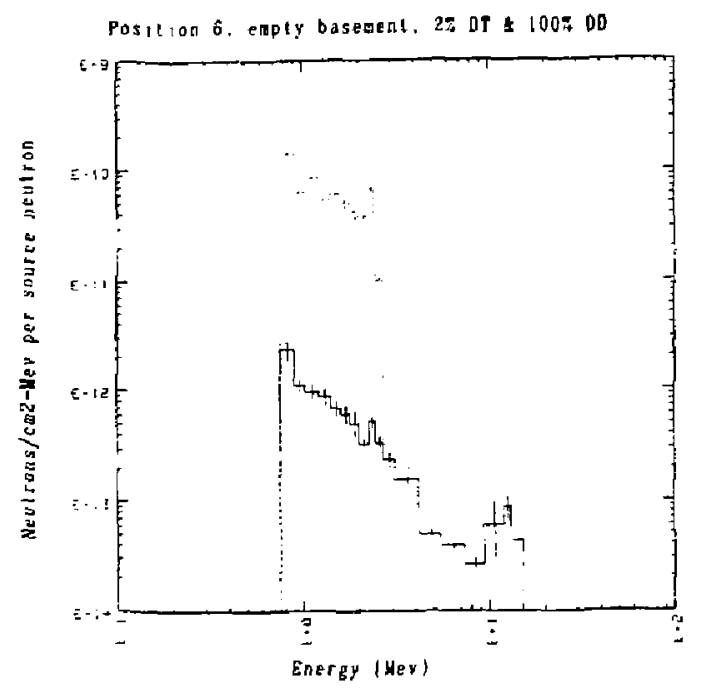

Fig. 14

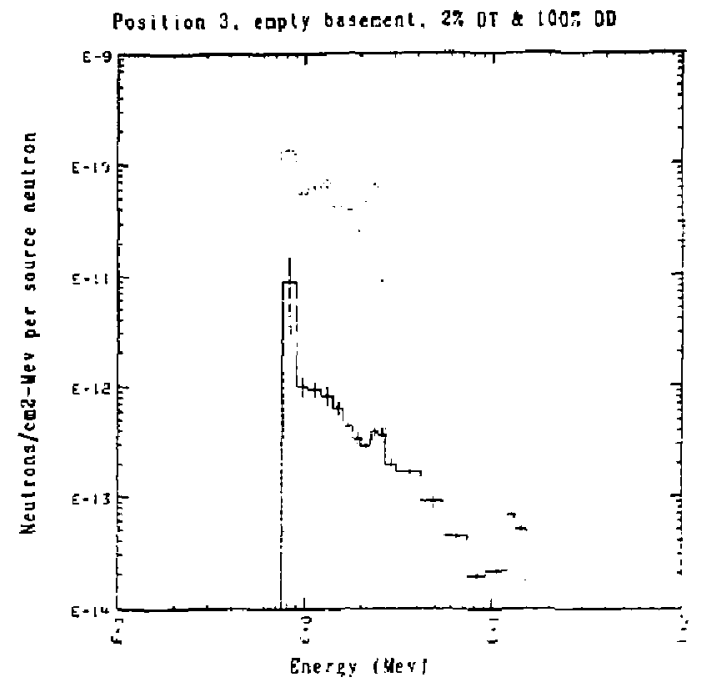

Fig. 13

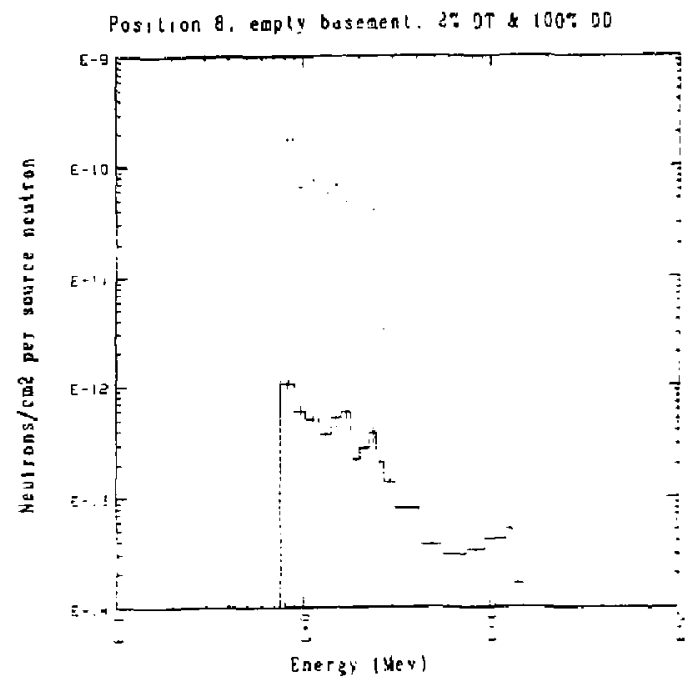

Fig. 15 




Fig. 16



Fig. 18

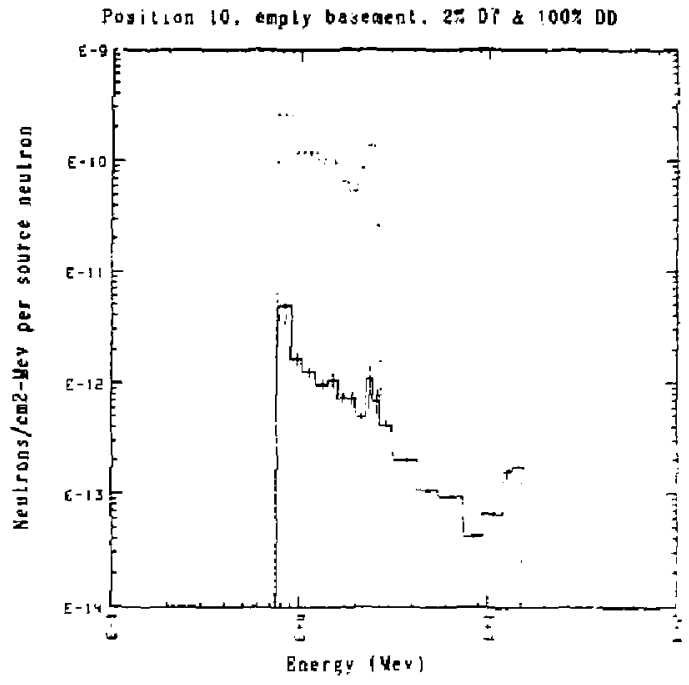

Fig. 17

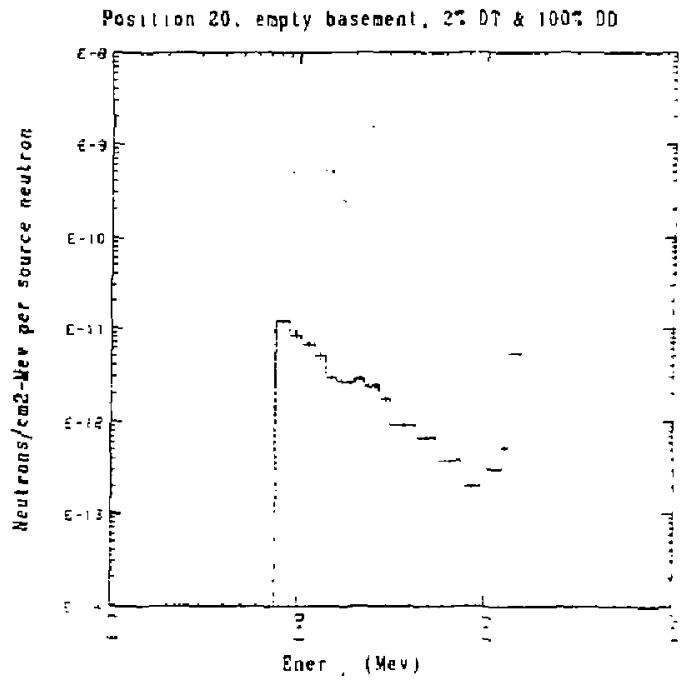

Fig. 19 


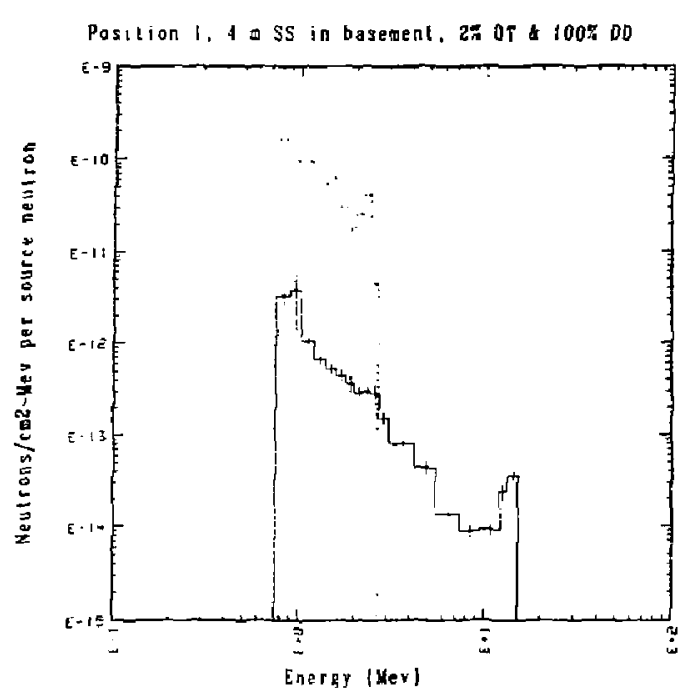

Fig. 20



Fig. 22

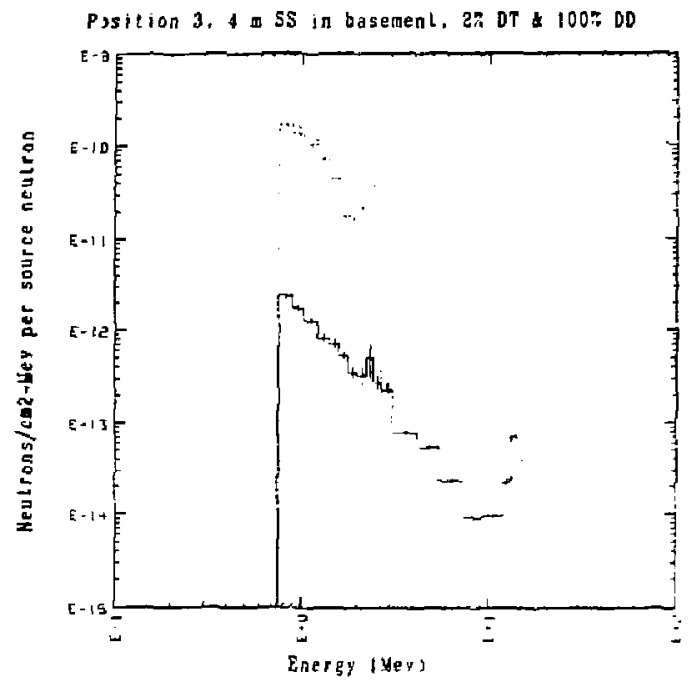

Fig. 21

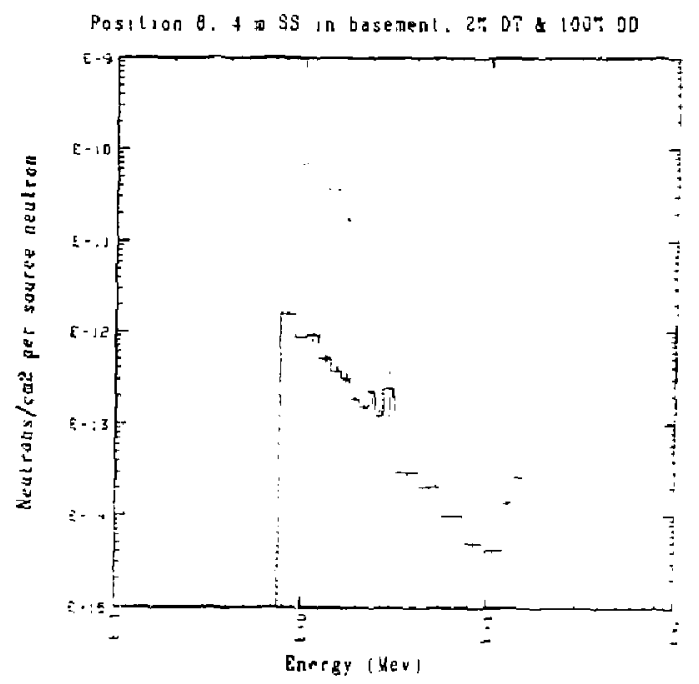

Fig. 23 


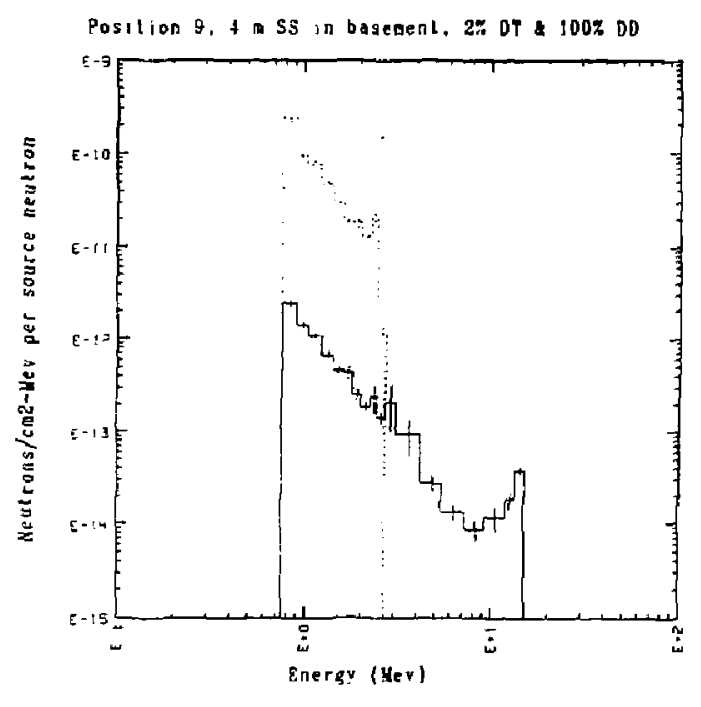

Fig. 24



Fig. 25

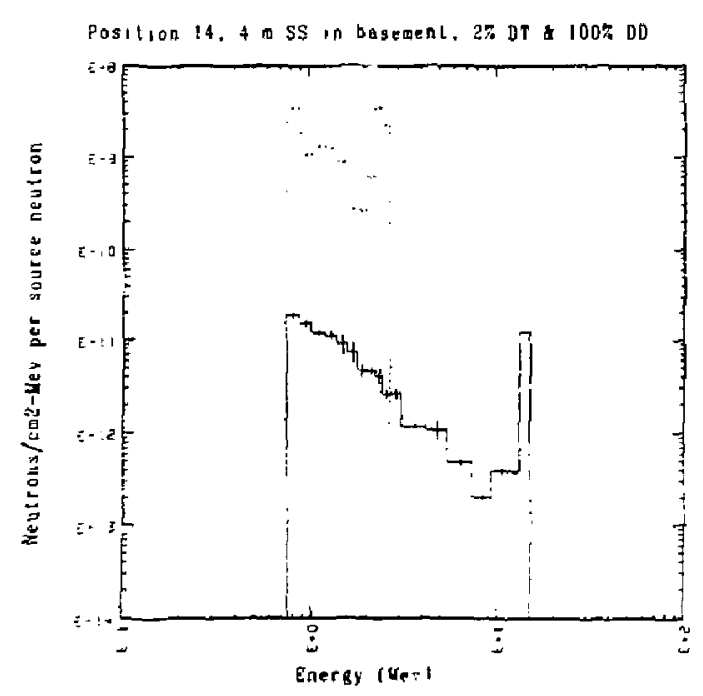

Fig. 20

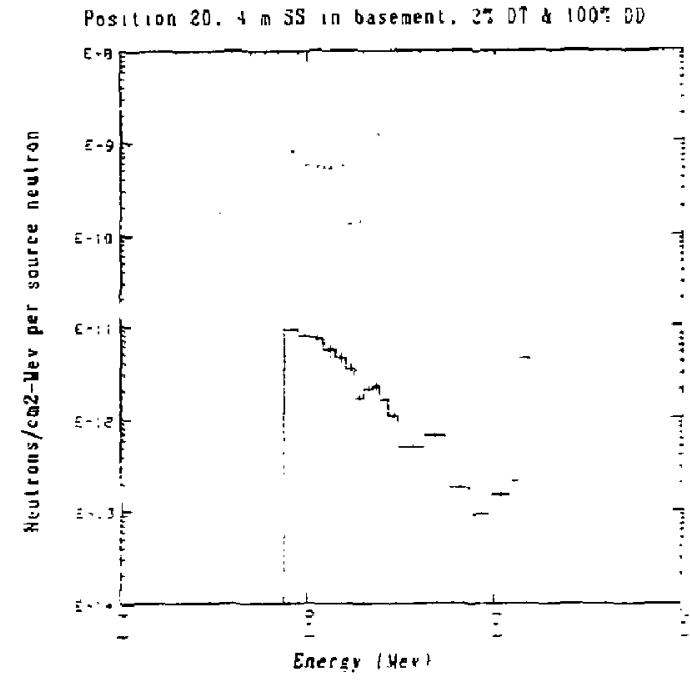

Fig. 27 


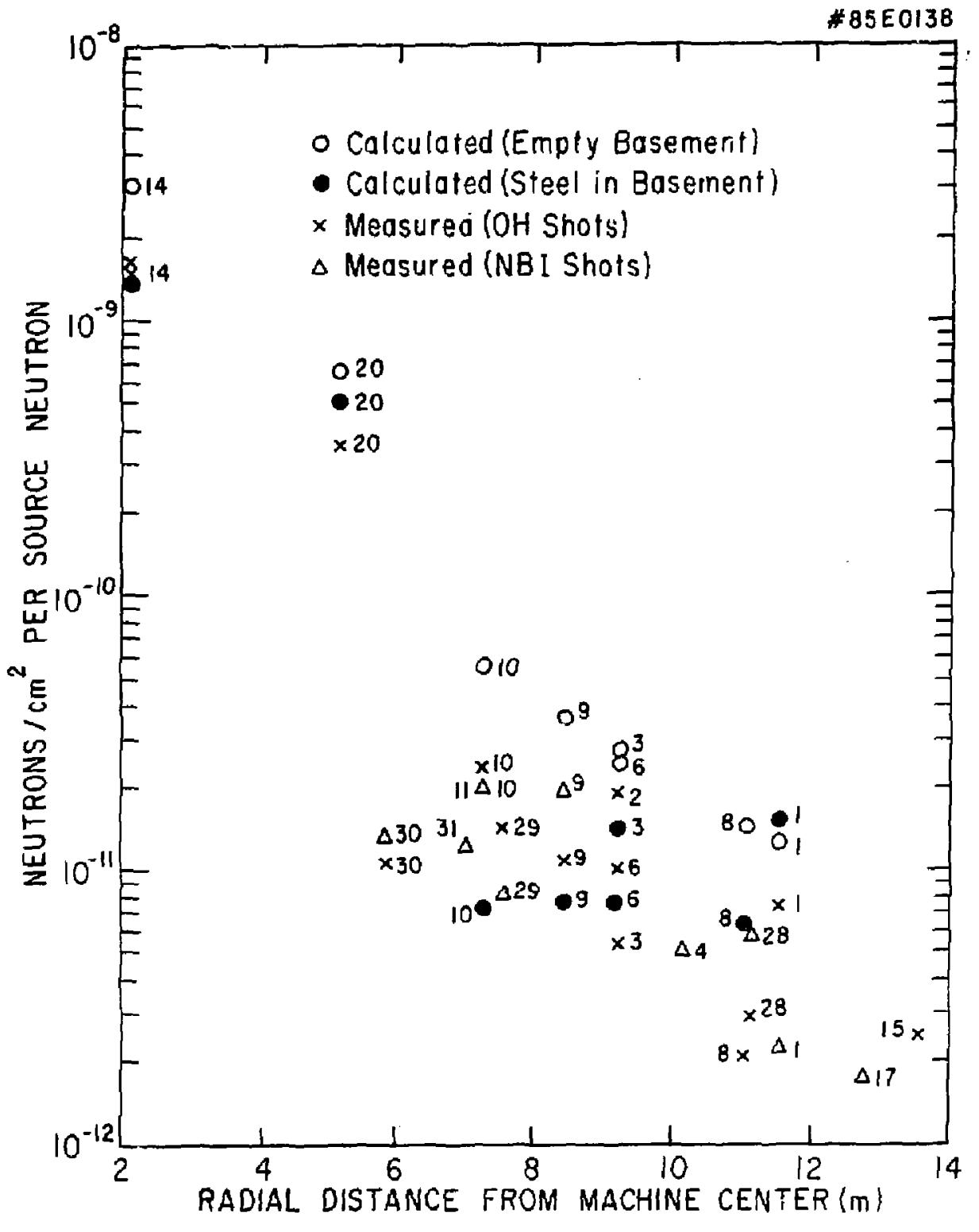

Fig. 28 


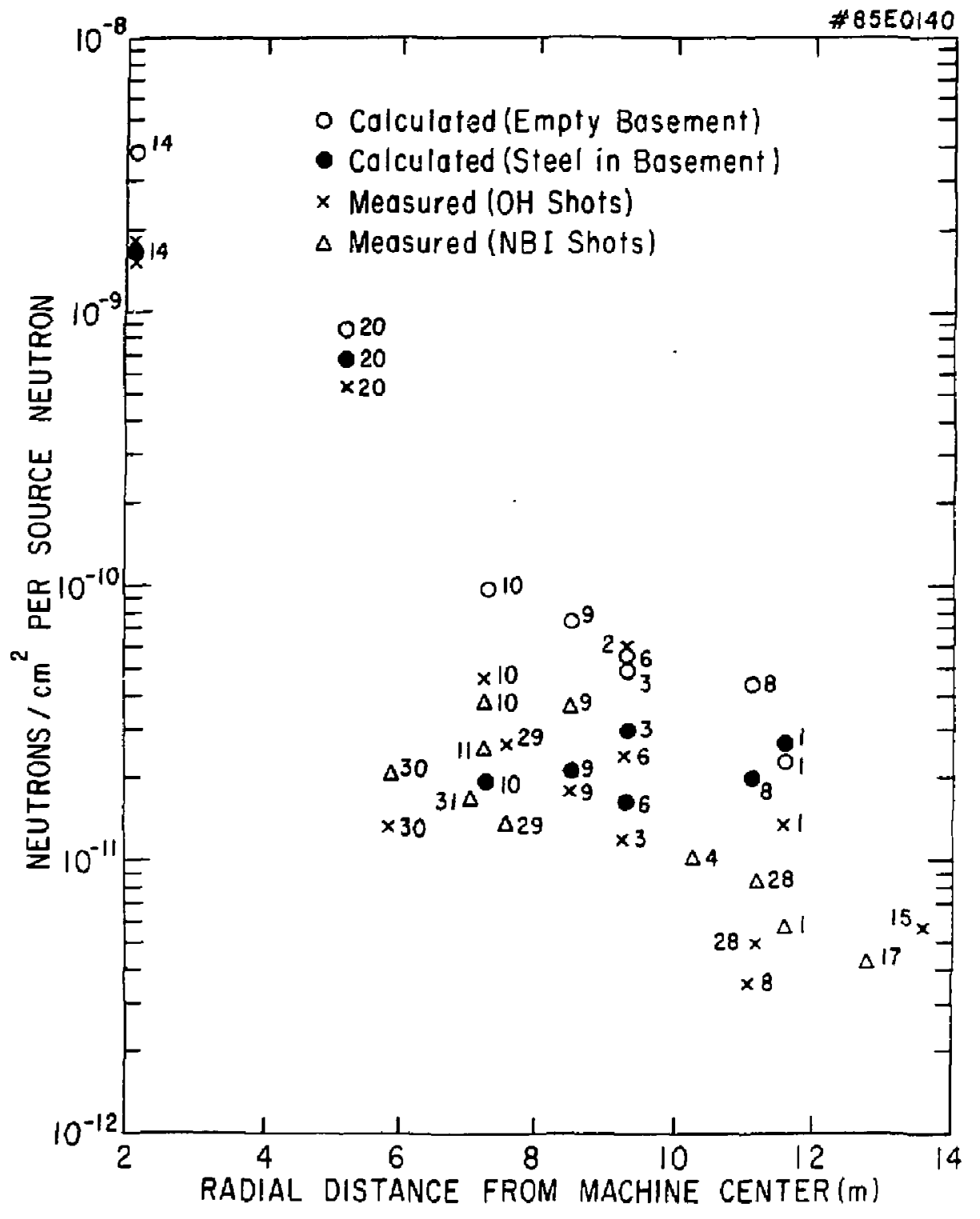

Fig. 29 




Eig. 30

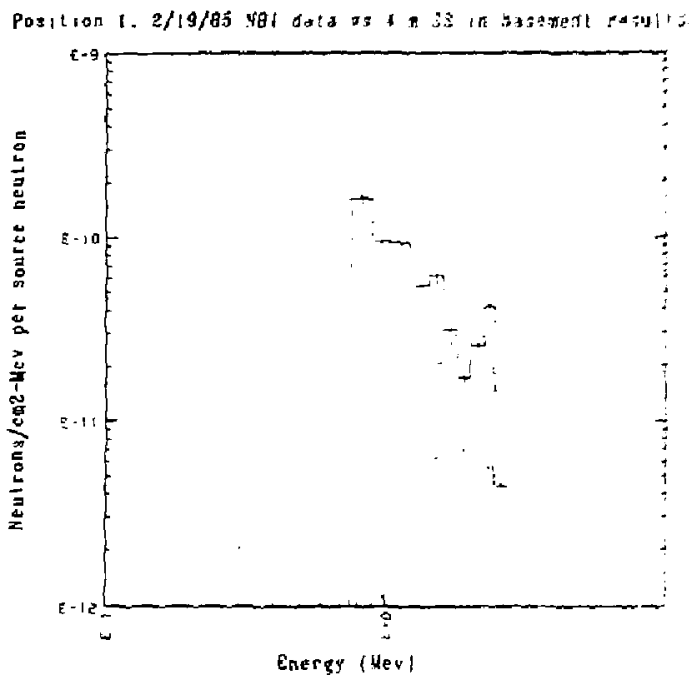

Fig. 31



Fig. 32

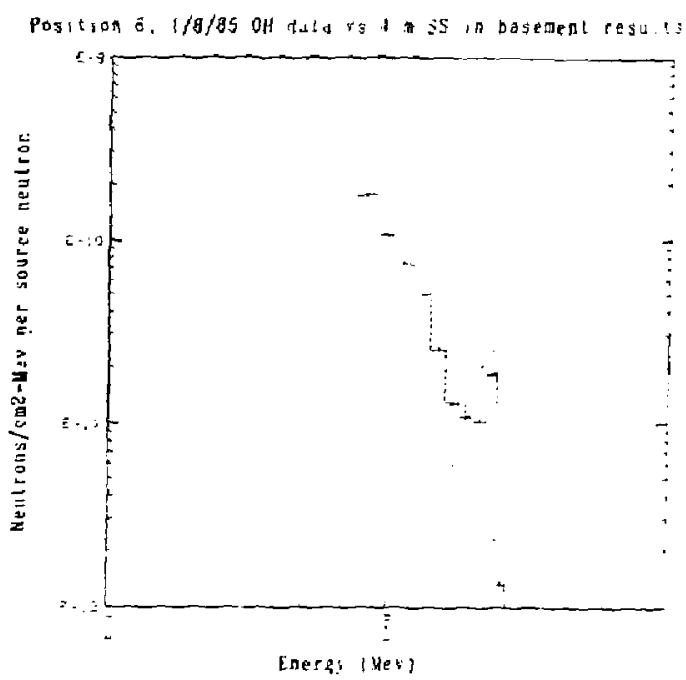

Fig. 33 


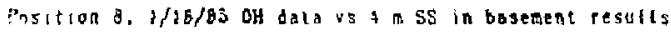

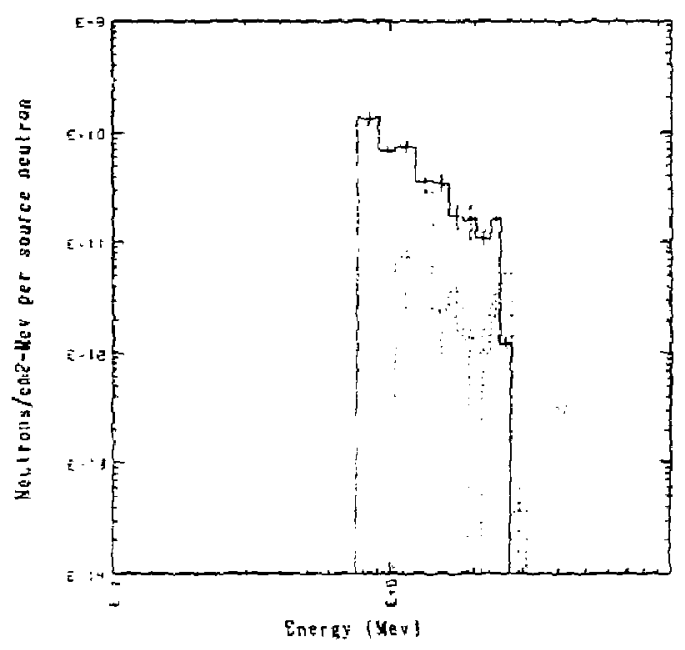

Fig. 34
Posilioa 9. 1/17/65 oH dala is I m $\Xi:$ in basepent results



Eig. 35

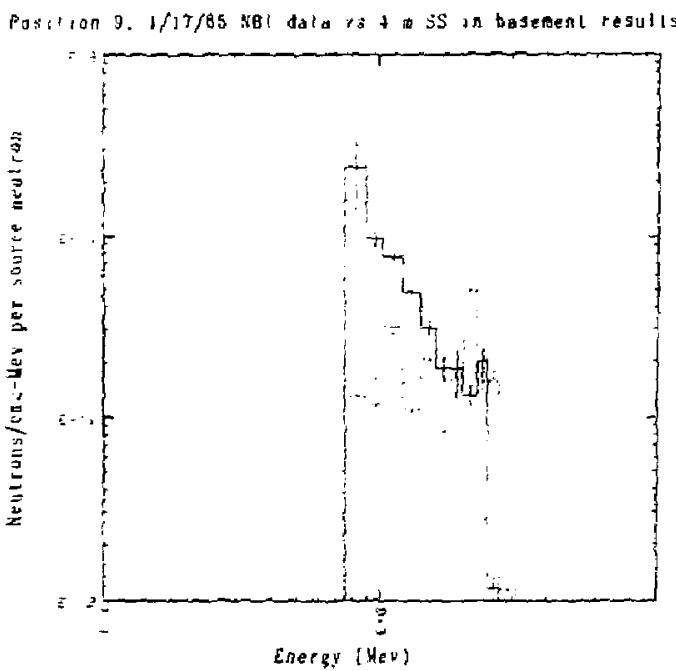

Fiz. 36

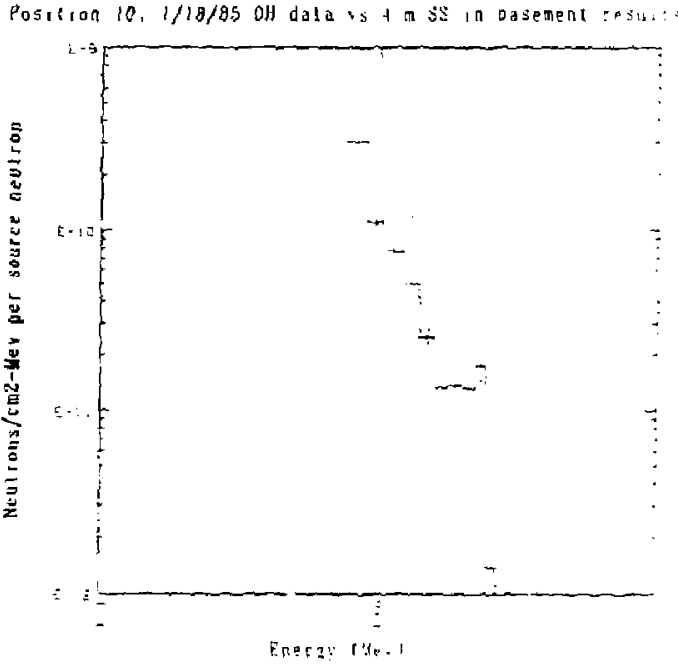

Fig. 37 




Fig. 38

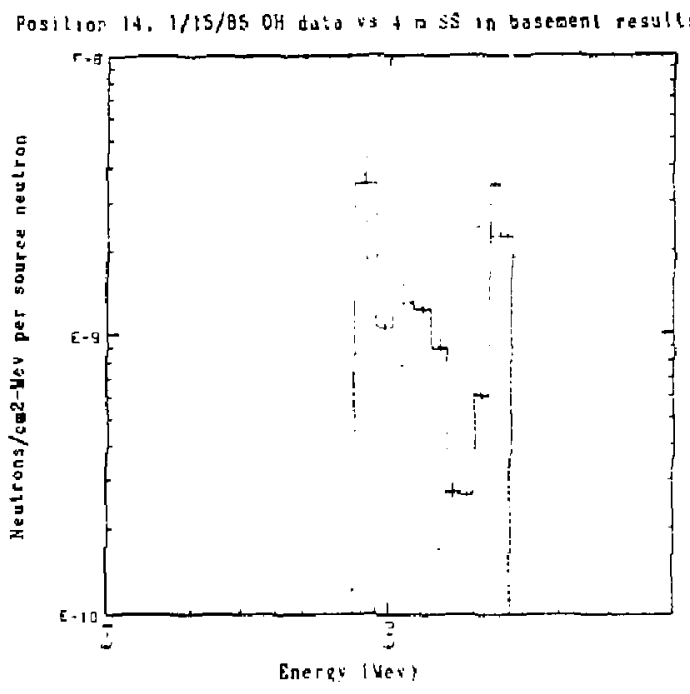

Fig. 39

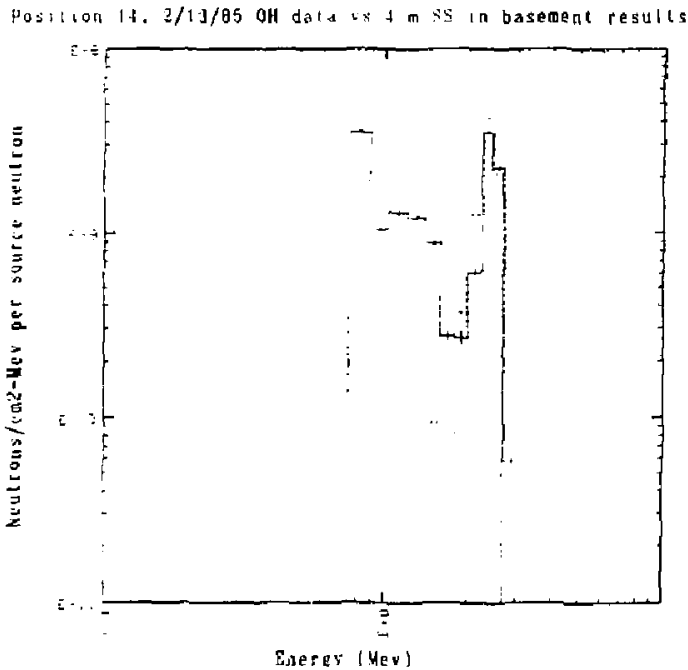

Fig. 40



Fig. 11 


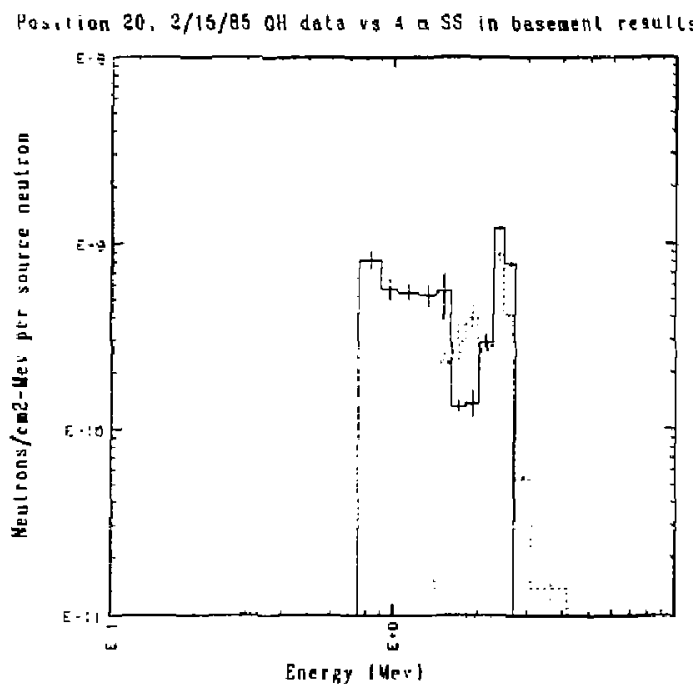

Fig. 42

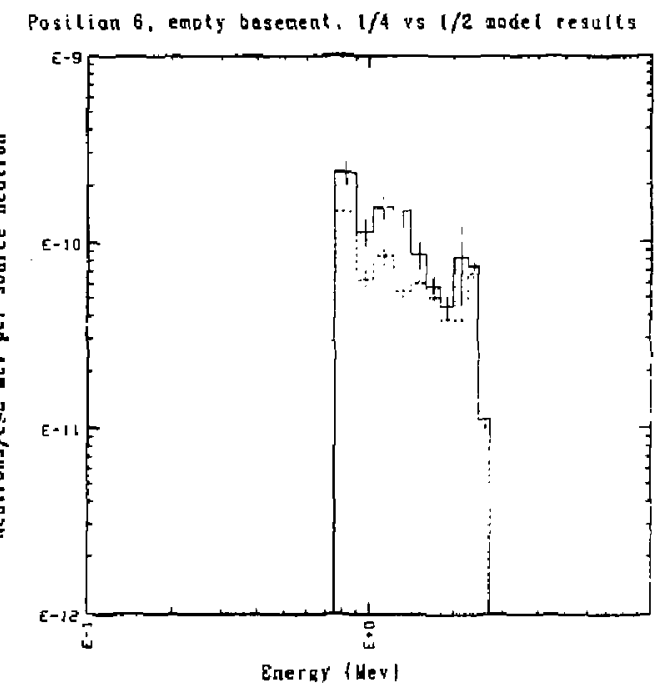

Fig. 43

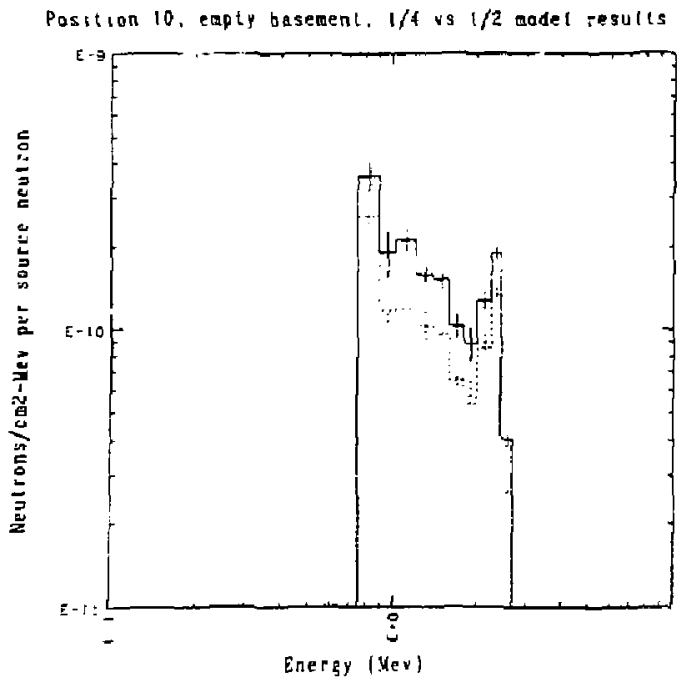

Fig. 44

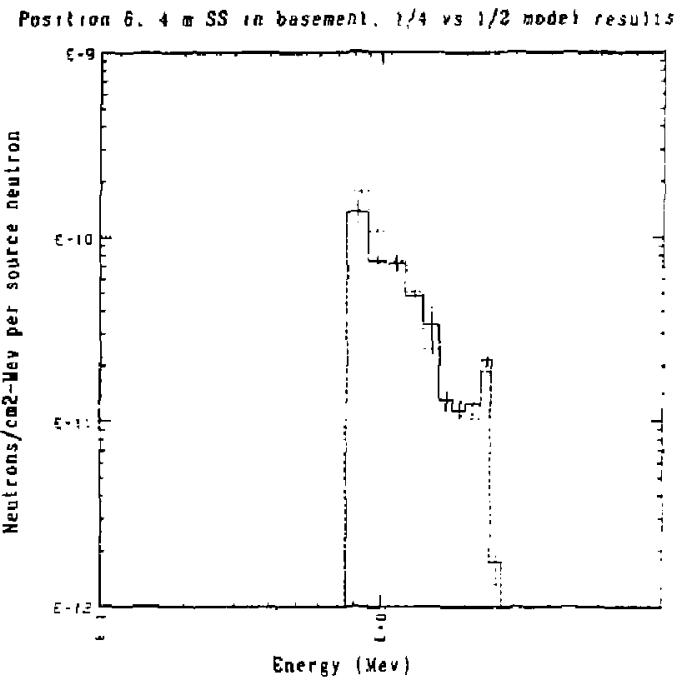

Fig. 40 




Fig. 46

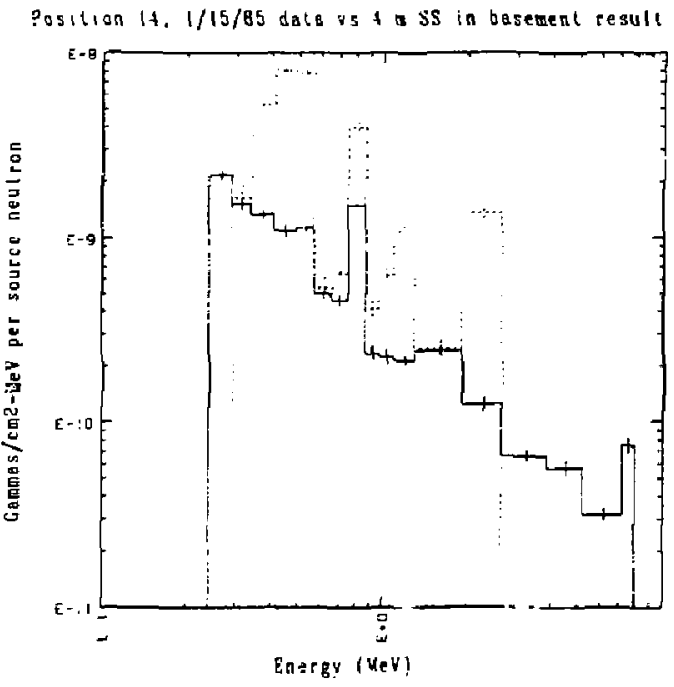

Eig. 47

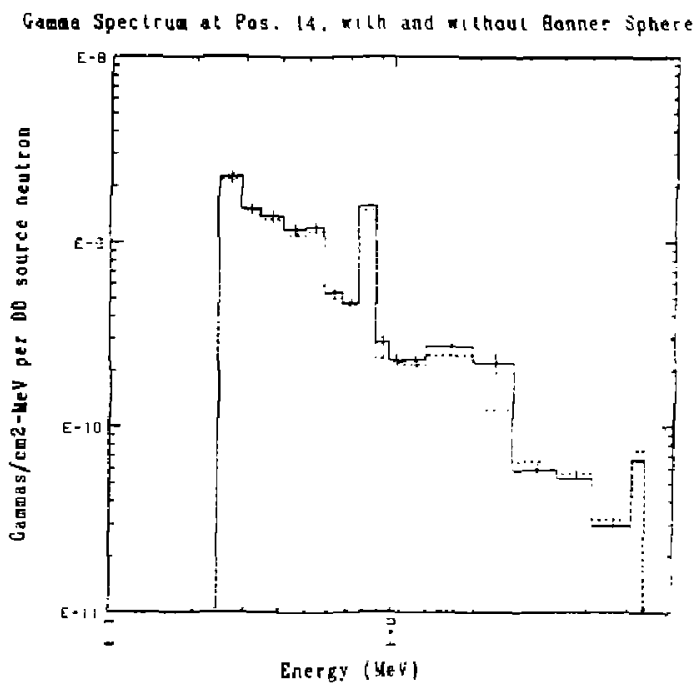

Fig. 48 
Plasina Res Lab, Alistra Nac'l univ, AusTratifa

x. Frark J. Paoloni. thiv of hollongang, australia.


PcoE. M.H. Erennan, Uhiv Sydrey, AUSTRArIA Prof. F. Cap, Inst Theo Phys, AUSIRTA Prof. Fraris Vechost, Inst theonetische, BEIGTUM


Eoole Royaln Militaine, Lab de Phys Plasmas, BEIGIM D. P. H. Sakanaka, Univ Estachal, ePATII D. C.R. Janes, Chiv of Alberta, CANADA Prof. J. Teichmarn, Univ of Mantereal, Curade Tr. H.li. Skarsgard, Uhiv of Saskatchevan, CANADA Prot. S.R. Steenivasan, University of Calgary, CANACA Pzof. Tutor iw. Johnston, INRS-Energie, CANaDA Dr. Harnes Bamard, Oniv British Columbia, CANADA OT. 1..P. Eachynsilo, MEg Tecinologies, Inc., CANADA Calk River, Nucl Lab, Carana

Zhengsu Li, \$N Inst Ehysics, CFWN.

ilibrary, Tsing tha thivensity, Crma

Librarian, Instibute of Physics, Crma

Irst Plasma Fojs, Acaderria Sinica, CIIIA

Dr. Peter Lukac, Kamensiceho Uhiv, CZECHOSTOMAKIA

The Iibcarian, Oulham Laboratory, ENGALD

Frof. Schatzman, Otservatoire de Misa, ERANCE

J. Ridet, CFHAPE, ERANCE

AM Dupas Tibrary, AM Dupas Iibrary, ERANCE

Dr. Ton Mtal, Acadeny Bibliographic, HONG KCNG

Preprint tibrary, Cent Res Inst Elys, tulNGiw

x. R.k. Ghajlari, vitran Chiv, INUIA

or. B. Desgupta, Saha Inst, IIDIA

T. F. Kaw, Physical Research Lab, IDIA

5x. Thillip Rosenau, Igcael Inst Tect, ISPAED

Froi. S. Oupentan, Tel Aviv University, ISRAEI

?rof. G. Rostagni, thiv di Padova, TIPLY

Libtarian, Inx'l atr theo Phys, IIALY

Miss Olelia de Palo, Assoc ERATOM-DNDA, ITALY

Biblivteca, del OK EURATOM, ILALY

Dr. H. Yamato, Doshiba Fes \& Dev, JAPAN

Jirec. Depr. Lg. Tokanak Dev. JAPI, JAPAN

Prof. Nobuyiki Inas, University of Dokyo, IRPAN

Resaird Info Center, Magoja hiversity, JAPAN

Erct. Kojji itishikeata, univ of Hiroshima, IAPAN

Prof, Sigen Mori, JARRI, JAPAN

Prof. 5. Tanaka, Kyoto University, JapaN

iiliscary, kyoto University, JaPAN

Prof. Ichiro Kawakani, Mihon Univ, JAPAN

zrot. Satoshi ttoh, Kyushu Univergity, Japay

Dr. D.I. Gnai, Adv. Inst Sci \& Tedt, KOREA

Iech Info Division, KAERI, KOREA

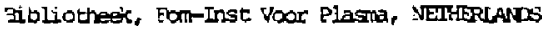

Prof. 3.5. jiley, Iniversity of haikato, NGA GFALAND

2rof. J.A.C. Cabral, Inst Guperior Tecn, pOFTUGaL
Dr. Dctavian petnus, ALI IJLA university, ROMANIA Prof. M.A. Hellberg, universigy of katal, 50 APkTCA Dr. Johan de Villiers, Plasma Zhysics, Nucor, SO APRDia Rusion Div. tibrary, JPN, SPADN

Frof. thans Wilhelmson, Chalmers thiv Tech, SWbow or. Lennart Stenflo, University of UMEA, SWDEN Library, Royal Inst Iech, saved

Centre de Recherchesen, Ecole Polytech Fed, SHITLENAL: DT. V.T. Toldk, Khadkov Phys Tedh Ins, ISSR

Dr. D.D. Ryntov, Siberzan Acad Sci, USSR

Dr. G.A. Eliseev, Kurctabov Instibite, ISSR Or. V.A. Glukhilkh, Inst Electro-Physical, ISSR Instibute Gen. Physics, ISSR

Prof. T.J.M. Boyd, Guiv College N hales, wALES Dr. K. Schindlex, Ruhr Universitat, W. GErtANY inclear bes estab, Julich Lta, w. Gruany libearian, Max-flandx Institut, H. GermaNY Bibliothek, Inst elasmaforscturtg, w. IBMMANK Prof. R.K. Janev, Inst thys, Yugustavia 